\title{
REQUIREMENTS FOR SPACE PROPULSION SYSTEMS
}

\author{
by
}

Ward W. Wilcox and Robert H. Rollins, II Office of Advanced Research and Technology NATIONAI AERONAUTICS AND SPACE ADMINISTRATION $\sqrt{ }$

Washington, D. C.
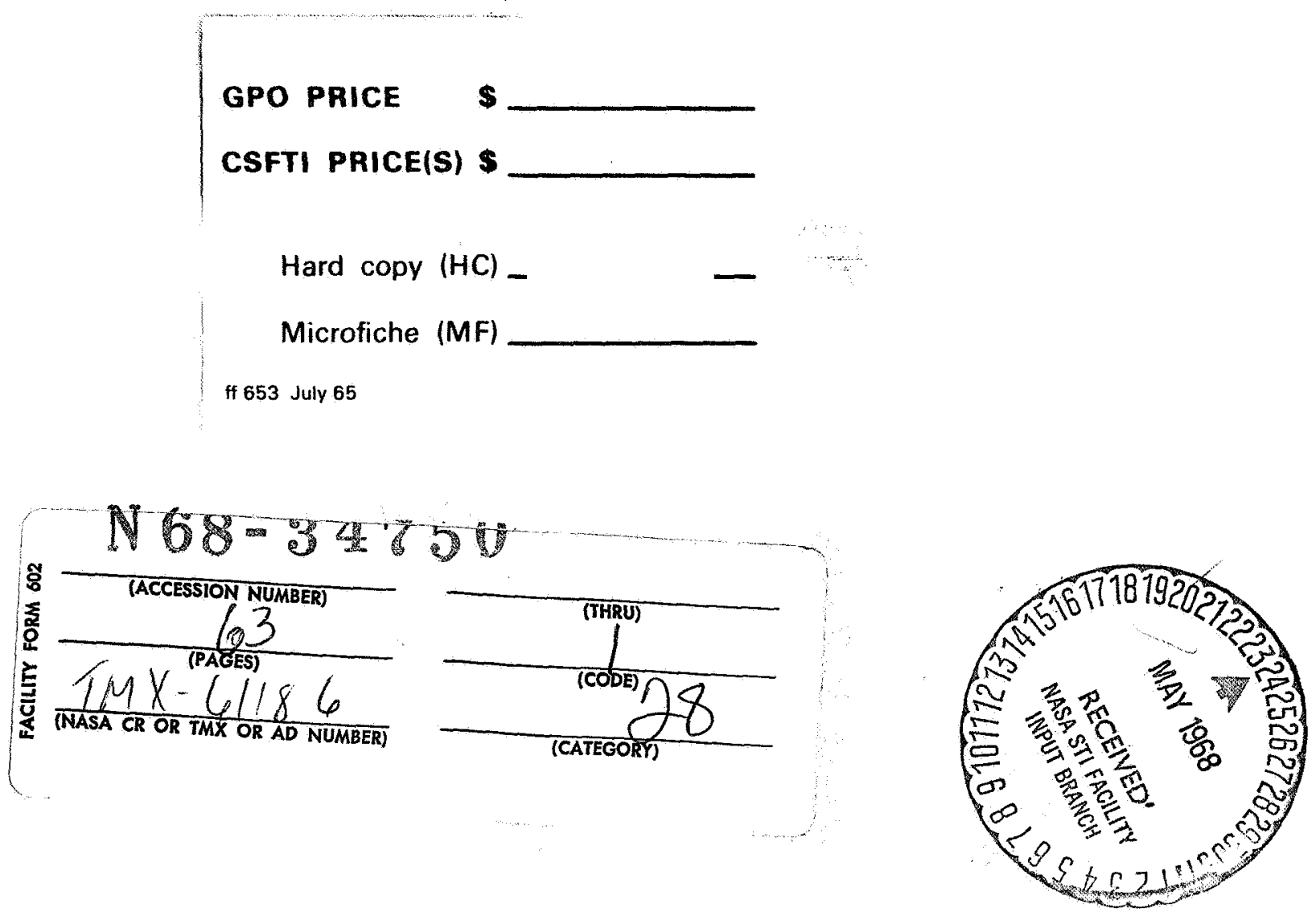
THE TITLE OF THIS PAPER is broad enough to encompass the history and future of space transportation. To remain within the scope of this session, several arbitrary limitations must be made. We will attempt to treat only requirements for propulsion in space, that is, thrusting devices used in and beyond earth orbit. The time period involved lies in the next decade or so depending more upon funding than technology.

The paper will be divided into three sections which will treat the following questions. First, where must the system operate? The environments in which the propulsion system will have to operate are shown in Table I. Some of the systems under consideraion will see all of these environments during a mission. The classical military specifications for sand, saltspray, fungus, dust, and $-65^{\circ} \mathrm{F}$ temperatures obviously won't suffice here. secondly, what must the system do? The performance and design parameters listed on Table II will be discussed generally in this section. Some of the parameters toward the end of this list can and do compromise the often-quoted high performance of advanced technology systems.

The third question we will attempt to answer is: How might the job be done? How can the desired performance goals be met in the environments which will be met? Several missions will be used to illustrate the problems involved in answering the "what must be done?" question within the "where must it be done?" framework. The additional problems of integrating the propulsion system into the spacecraft will also be noted in these illustrations. We will attempt, in this final section, more to raise questions than to provide answers. The three presentations which follow this paper are oriented toward providing the answers.

Ward W. Wilcox \& Robert H. Rollins. 
Before proceeding any further, we would like to make two other comments. First, this paper does not represent an official NASA position or plan and presents only personal opinions and observations. Secondly, we are prejudiced, mainly by experience, in the direction of chemical liquid rocket engines. While observations will be made on nuclear, solid, electric, and hybrid propulsion, the majority of the talk -- and we suspect of the propulsion for the next decade -- will be on liquid rocket systems. This prejudice is not completely out of line, however as shown in Figure 1 . which compares trip times to nearby planets. Chemical rockets will do the job well from Venus to Jupiter and there are those who say Jupiter's mass can be used in a swingby mode to go anywhere beyond Jupiter without penalty.

\section{OPERATIONAI ENVIRONMENTS}

VACUUM ENVIRONMENT-Spacecraft

engines are typically considered to operate in an absolute vacuum and usually after long periods of vacuum soak. Although the vacuum of space is uniform, the thermal environment is not. Because thermal radiation from the sun follows straightforward rules, average values in the vicinity of the spacecraft are readily determined. However, variations from the sunny side to the shaded side of the spacecraft are much greater than the variation in average temperatures over millions of miles of distance. Figure 2 shows the general variation of temperature with distance from the sun over a 100 to 1 band of spacecraft absorptivity/emissivity ratio. In the Venus, Earth, Mars neighborhood, average temperatures are quite warm (except in shadow of earth or moon) while beyond Mars, temperatures are in the cryogenic range. While the general thermal and vacuum environment influences the operation of all system components, the greatest influence is felt by the propeliant

Ward W. Wilcox \& Robert H. Rollins, : A titin. 
storage system as will be discussed later. Storage temperature tolerance of three broad classes of propellants are shown in Figure 2, defined by temperature into earth storable $\left(650-470^{\circ} R\right)$, space storable (or mild cryogenic) $\left(300-90^{\circ} R\right)$ and the deep cryogenic, liquid hydrogen $\left(50-25^{\circ} \mathrm{R}\right)$. The treatment of a simple spherical shape in Figure 2 may be modified by deliberate orientation of the vehicle and selective emissivity control. In the deep space environment, the location of the sun relative to flight path may be considered to be constant and tech-i niques such as shadow shielding may be considered. In a gravity-constrained flight path orbiting a planet or satellite, trade-offs must be made against the control requirements to maintain constant solar orientation. In both cases, of course, the demands for thermal control of the total vehicle. and communications, guidance sensing and solar power orientation must also be considered. Other considerations of operations in a vacuum environment are concerned with influence of propulsion on the spacecraft itself. Leakage or intentional venting can disturb the attitude of the vehicle. Many scientific observations are obtained inferentially from minute deviations in the observed location of the spacecraft, or from occultation of the signal by a planet. Any influence of leakage or propulsion anomalies could make such observations useless if known, or lead to false conclusions if unnoticed. The problems of propellant positioning in a zero gravity environment are well known, qualitatively if not quantitatively. Each of the various active or inactive devices used has its own set of pros and cons. Again, a choice has to be made based on trade-offs which may impact the engine choice.

Ward W. Wilcox \& Robert H. Rollins, IJ Aublus his: 
main propulsion system at throttled or idle-mode conditions should be made available to the spacecraft designer. The products of combustion or propellant leakage can coat optical surfaces and thus disable guidance devices or degrade solar cell operation. In the case of manned spacecraft, all the effects of discharging toxic or corrosive chemicals into the vicinity of a spacecraft in a vacuum are not yet known. It is possible that some crystalline products might be tracked into the cabin after an extravehicular operation. Earth storable and space storable liquid propellants and some solid propellants contain toxic and corrosive elements, while the hydrogenoxygen system has the least obnoxious end product-water, in the form of ice. Those of you who have had to scrape icy windshields will appreciate that difficulty even in our customary environment.

ATMOSPHERIC ENVIRONMENT - While a "space" vehicle spends the majority of its life in a vacuum, some of the most demanding criteria are provided by short exposures to atmosphere. All spacecraft endure an interminable period on the launch pad and a rough trip on the launch vehicle before they leave earth. Some will again enter the earth's atmosphere, while others must cope with entry into planetary atmospheres.

The thermal environment during atmospheric operation is transient, but can provide high peak heat loads which are not only a problem in propellant storage but also in protection of exterf nal elements of the system. For this reason, all of the Gemini engines (Figure 3) were faired into the external skin of the vehicle interface area. Ward W. Wilcox \& Robert H. Rollins. II As the entry demands are generally more severe than launch, the Apollo Command Module employs buried engines, while its Service Module engines are designed to take only launch heat loads. 
In addition to thermal protection

for atmospheric operation, vibration and acceleration forces require design consideration. Aerodynamic buffeting and high sound levels combine to provide severe vibration spectra. Superimposed are the peak acceleration loads during launch and entry. Suffice it to say that the structural criteria for the spacecraft and its propulsion components are drawn primarily from the short time the spacecraft passes through the atmosphere.

SURFACE ENVIRONMENT - The earliest environmental considerations given in space propulsion design are those required to operate on the earth's surface, as the majority of the development of a system is conducted in that environment. The thermal environment may be somewhat modified so as not to require great compromise for vacuum operation. Acceleration forces may be held to low levels and the system may be isolated from vibration. Thus, the vacuum and atmospheric environments previously discussed provide the specifications for the majority of design criteria and ground based simulation of these extremes is generally required during development. Maintaining a good vacuum for long duration firings, even with modest thrust ratings, is an expensive proposition. Furthermore, it is hard to visualize tying up a high vacuum facility for 300 days to get a realistic vacuum soak. Another major impact of surface operation on the spacecraft propulsion system falls in the areas of contamination and safety. On the earth's surface. "clean room" operations are generally accepted as necessary for protection of the engine from the hostile environment in which man exists. When consideration is given to operation in an extraterrestrial atmosphere and on surfaces where this type of laboratory treatment is not available, additional design constraints will be necessary. The safety

Ward W. Wilcox \& Robert H. Rollins, I: Anlins mis: 
of a propulsion system in the human environment is considered to be a performance-oriented requirement and will be discussed later.

\section{PERFORMANCE}

In answer to the question, "What is the system required to do?", a long list of performance parameters has been compiled. Thrust levels range from very low levels for auxiliary applications such as attitude control, rendezvous, and docking, to tens of thousands of pounds for planetary capture and landing of large spacecraft. Thus, technology must be available over the complete thrust spectrum as shown generally in Figure 4. While this figure shows principal areas of application for various types of propulsion, the overlap regions should be emphasized as being necessary and desirable. only by having these options available can the spacecraft designer make real optimizations. SPECIFIC IMPULSE AND DENSITY - The most common parameter for discussion of propulsion performance is specific impulse, or the energy available from a pound of propellant. Figure 5 shows the variation of specific impulse and. bulk density with mixture ratio for three classes of propellants. As the figure shows, the propellants with highest performance, deep cryogenics also have the lowest bulk density. thus requiring greater tankage volume. Beyond the range of the chart lies the nuclear reactor systems, with specific impulse above 800 and a lower density of $4.4 \mathrm{H} / \mathrm{ft} .^{3}$. On the other hand, the lower specific impulse earth storables have highest density which tends to compensate in terms of overall weight. The space storables, which are receiving a lot of attention these days, fall in between on both scores, having reasonably high per formance and good bulk density.

Ward W. Wilcox \& Robert H. Rollins, I 


\begin{abstract}
STORAGE TEMPERATURE - The normal
\end{abstract}
storage temperature range of several

of these propellants is shown in Figure 6.

Without dwelling on each of the possible.

combinations, it should be pointed out

that hydrogen is in a range by itself. several of the space storables have overlapping temperature ranges in the mild cryogenic region, and that earth storables freeze at relatively high temperatures.

The interrelationships of various propellant choices are better shown in Figure 7 which compares the volume of the three classes of propellant on the basis of equal propellant weight, as would be the case where this stage size is limited by an existing launch vehicle. It is obvious that the hydrogenoxygen stage imposes packaging restrictions even in this simple arrangement. As will be shown later the problem is more severe in an integrated spacecraft where propulsion is intermingled with other spacecraft components. CONTROLS - The effects of the engine control or duty cycle requirements are frequently far-reaching. One can arrive at a desired velocity increment by a series of pulsed firings or by a throttleable single firing. The optimum method depends on characteristics of the guidance and control systems as well as on the features of the engine. Both overall reliability and optimum use of propellants are involved in the tradeoff studies. Usually engines which do not depend on regenerative cooling, are called on to handle the short pulsed firings. For longer duration firings both pressure-fed non-regenerative and pump-fed regenerative engines may be selected. No clear cut dividing line exists between the pressure-fed and pump-fed engine regimes although the trend toward higher chamber pressures to reduce engine size lowers the thrust level of the cross-over point as technology advances.

Ward W. Wilcox \& Robert H. Rollins, I: whis., us: 
IGNITION - Another consideration in choice of propulsion systems is the ease of ignition in vacuum. Such propellants as the earth storables, $\mathrm{N}_{2} \mathrm{O}_{4}-$ MMH, are hypergolic and do not need a separate ignition system. However. after a long soak in vacuum and when metal parts have become very cold, hard starts have occurred with these propellants. In some cases detonable intermediate compounds are formed which collect in the chamber and are triggered by the next engine firing. Even when such compounds do not result from the tail-off of a previous firing, the discharge of the first few drops of propellants into vacuum can cause frozen particles and/or ignition delays. Minimum volume between valve and thrust chamber is highly desirable. Although most propellant combinations under consideration are hypergolic under sea level conditions, the detailed characterization of vacuum ignition problems requires thorough investigation. STERILIZATION - A general consideration for spacecraft propulsion is the need for sterilization beyond any earth bound requirement for all spacecraft which have any chance of landing on a planet. Currently, the only acceptable method of sterilization is that shown in Figure 8, i.e.. 6 heat cycles of $60 \mathrm{hrs}$. each of $275^{\circ} \mathrm{F}$ and sterile storage thereafter. Tests of an earth storable bipropellant system over this cycle have recently been successfully conducted. Obviously, if you are to seal the propellants into their tanks and then raise the temperature to $275^{\circ} \mathrm{F}$, a low vapor pressure is necessary and cryogenics are ruled out. This leaves only the earth storables or solid rocket motors. Efforts are currently underway to work out acceptable techniques by which sterile liquids can be transferred to sterile spacecraft.

Ward W. Wilcox \& Robert H. Rollins, I 
SAFETY - Ideally, one would prefer to use propellants which would be tanked days or weeks before a launch, checked out and forgotten. This never seems to be the case. By their nature, propellants are fire hazards and could explode or detonate. Most of the oxidizers are toxic to humans and hazardous to plants. Fuels such as diborane are pyrophoric - - that is they ignite spontaneously in air, and the fuel oxidizer combinations are usually hypergolic. Obviously leakage and venting have to be handled carefully? and mechanics will feel uncomfortable working on spacecraft containing loaded propellant systems.

In addition to these problems, for any propellants requiring storage at low temperatures, insulation is a problem because the type of insulation which works best in the vacuum of space is virtually useless in an atmospheric environment. Therefore, a separate approach to ground-hold insulation or special methods of topping off or refrigerating propellants during launch countdowns and holds are required. The tradeoff between system complexity prior to launch and prior to operation in space frequently influences choice of alternate systems.

In our discussion so far the matter of cost has been disregarded. This is a factor which influences all aspects of system choice, directly and indirectly. One way to look at cost is demonstrated by Figure 9, which shows a transportation cost in dollars per pound vs. total velocity. In other words these costs are those necessary to deliver a spacecraft propulsion system to the point of use. Obviously. the greater the delivery expense prior to use the more justified are efforts to improve performance and reduce weight. The upper curve shown represents a onetime use including operations cost
Ward W. Wilcox \& Robert H. Rollins, I 
while the lower curve represents recurring costs only.

FUTURE MISSION REQUIREMENTS

Up to this point in the presentation we have been able to list and discuss environmental and performance parameters that will affect the specifications for future spacecraft development. A valid recommendation may be made that environmental criteria for the several operating regimes discussed should be prepared and approved by the user agencies to assist future development planning. Many studies have been conducted which have considered performance tradeoffs for specific missions, utilizing state of art performance factors, but which have not necessarily used consistent and completely defined environmental criteria. It shouldn't be too difficult to arrive at a compendium of acceptable parameters. Propulsion system performance may be put into criteria form also, but this is a more difficult task. Evolving technology which produces new propulsion concepts and improves on existing ones is probably more disruptive to criteria stability than the improvement expected in environment definition. Secondly, there is no choice in the selection of environment when a mission goal is selected, while a wide gamut of performance factors may be considered in the selection of an optimum system.

As an attempt to put the mission spectrum in focus, it has been the custom of the Office of Space sciences to project future needs for unmanned exploration over a 20 year period. A list of some of the missions of interest, along with pertinent parameters is given in Tables III and IV. Table III lists unmanned planetary probes and Table IV gives some possible synchronous equatorial orbit missions.

Ward W. Wilcox \& Robert H. Rollins, I inlins now 
The most obvious conclusion from

the tables is that all of these payloads are within the capability of current launch vehicles. Another is that there is a wide variation in trip time and propulsion system weight requirement. In many cases all three classes of propulsion as discussed earlier could be considered for a given job. This allows the mission planner and the spacecraft designer the maximum flexibility in trading off the various restraints and attributes of his system. It is expected that each new requirement will use existing systems as a baseline for comparison of advantages of proposed improvements. In order to make technically sound decisions it is important that the improved technology be demonstrated in a working breadboard system with realistic operating conditions. While there is little dispute over the previous discussion, we now bore into the never-never land of future planning. The future misions to be discussed are just that -- they lie in the future, and all attempts to define when that future may be, seem to end with emotional pleas and frustration. This paper makes a deliberate attempt to show that many choices exist, but does not echo any of the pleas presented by advisory groups, academies. ad hoc working groups, or annonymous prophets.

PLANETARY MISSIONS - As an extreme example of the variety of spacecraft propulsion requirements which can exist in a single mission, a Manned Venus-Mars Flyby Mission with sampling of the Martian surface will be discussed. Figure 10 shows a 4 man spacecraft packed with orbiters and landers for both Mars and Venus. In addition to all of this equipment is the propulsion module which injects the spacecraft on its interplanetary voyager. This unit

Ward W. Wilcox \& Robert H. Rollins, I might require anywhere from 50,000 $1 \mathrm{bs}$. to $200,0001 \mathrm{bs}$. of thrust to eject the 
spacecraft out of its elliptical assembly orbit and might just as well be considered part of the launch vehicle for purposes of this discussion. The chances are that liquid hydrogen would be used in this application, either in a nuclear or a chemical rocket stage, due to the relatively short storage times required and the high performance available.

During the long voyage to the first planet of interest there will be many requirements for attitude changes to allow scientific observations and transmission of data back to earth. In addition several course corrections may. be needed. Because of the variety of corrections to be applied multiple locations of relatively small thrusters are required similar to the arrangement shown in Figure 3. Total impulse and thrust requirements for these auxiliary: propulsion functions are such that a wide range of electrical as well as chemical systems may be considered. The major events in the trip trajectory are shown in Figure 11 . Total trip time, according to the studies of North American Aviation reference 1, are of the order of 500 days.

In the vicinity of the first planet, Venus, the spacecraft requires maneuvering propulsion to allow scientific observations with a variety of instruments. Several probes are deployed, both to orbit the planet and to descend to the surface. The orbiter probei requires propulsive maneuvers to separate from the flyby trajectory and decelerate to an orbiting station. Additional burns for orbit trim or plane change may be expected. Such an orbiter might look a good deal like the illustration of Figure 12 although this specific design is for an unmanned application. Here you can see that

Ward W. Wilcox

Nines: the propellant tanks are packaged within an insulated shell which provides 
the ground hold environment on the launch pad. In this concept the tanks are filled with cryogenic propellants before mating to the launch vehicle, kept refrigerated until

launch and kept sealed (unvented) until used. Obviously the demands on technology will be high, as previously discussed, in areas of insulation and thermal management. In the case of a large manned spacecraft, filling the tanks just prior to deployment is possible, although a new set of problems would be introduced.

At the planet Mars, orbiter probes are again deployed and a Mars surface sample return probe has been proposed which would separate, land and rendezvous with the spacecraft, bearing samples of Martian soil. This type of operation has been studied in detail in Reference 1 and will be used here to illustrate propulsion problems only.

Figure 13 shows a Martian watching the aerobraker probe approach, land and take off with its samples. As you can imagine this return probe is at the far end of the cost vs. delta $V$ curve that we discussed previously and the best of everything we know is needed to be able to perform the mission at all. Looking first at the left side of the illustration we see the aerobraker configuration. Very significant reductions in propulsive requirements can be achieved by using the thin atmosphere to slow down the probe. However, the saucer-like shape of the optimum aerodynamic configuration imposes packaging limits on the spacecraft. In a specific configuration studied for a manned Mars lander, it was not possible to package the hydrogen for an $\mathrm{H}-\mathrm{O}$ system within the aeroshell because of diameter restrictions of the launch vehicle (Saturn V). In this case the Flox-methane propeliant combination was chosen. The final

Ward W. Wilcox

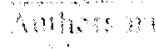

and 13 
landing is accomplished by means of throttleable liquid rocket engines similar to those used on Surveyor. Consideration has also been given to parachute deceleration which would decrease propulsion requirements. In order to take off from Mars and catch the fleeing flyby spacecraft. the sample return probe shown required three stages with excellent mass fractions and high specific impulse. In this example, the take-off stage of the three stage return vehicle would require specific impulse above 400 in a 1000 pound thrust unit using propellants which are dense for good packaging in the lander and storable both enroute to Mars and on the surface of Mars. A schematic arrangement of the three stage launch vehicle resting on the landing stage is shown in

Figure 14. Even in this schematic, the packaging problems are apparent and all the plumbing, wiring, controls, etc. are not shown. In order to be able to store mild cryogenics for the mission duration everything in the package would have to be exposed to vacuum and a long cold soak. During descent through the Mars atmosphere the ascent stages have to be protected from entry heating. Stay time of this probe in the thin Martian atmosphere might be of the order of two hours, limited by the requirements of catching the flyby vehicle. To accomplish the job described here, there are several areas of technology which need more attention. For these very small high performance engines, low capacity, high pressure turbomachines will be required and the ability to maintain throat dimensions will be taxed severely. Contemplation of the

Ward W. Wilcox Astis 14 
checkout of this miniature three stage launch vehicle in the time available might provide interesting simplifications applicable to earth launch vehicles.

IUNAR MISSIONS - If the sophisticated planetary missions discussed above appear to be too far in the future for consideration at this time, we can contemplate expansion of lunar surface operations. To support expansion of lunar operations, it is clear that a less expensive transportation system to the moon will be required. Most of the serious proposals include a cryogenic lunar landing stage (Figure 15) similar to those originally proposed for the Apollo direct landing missions. The transit time is no longer a serious barrier to the storage of liquid hydrogen and the lack of atmospheric entry heating completes the case for the use of oxygen-or fluorine-hydrogen systems in this application.

Advanced versions of a lunar ascent stage will probably be required if the lunar orbit rendezvous scheme continues to be used for crew return. Long surface storage times would favor earth or space storable systems as the crew capacity of the stage is increased.

On the surface of the moon a choice exists between "air" and ground transportation. It appears that a society that depends on rapid point-to-point transportation on earth won't be satisfied with some of the surface devices proposed for lunar exploration. Concepts for a Lunar Flying Unit have been under study for some time. The earliest version would be a simple one or two man platform (Figure 16) using throttleable earth storable engines, perhaps very similar to the current surveyor system. The current propellant choice which is dictated by expected earth storable bipropellants residual in the early lunar module tanks will probably evolve to the simpler

Ward W. Wilcox \& Robert H. Rollins.. IJ (a) 
monopropellants once a reasonable resupply service from earth is operational. The storability of hydrazine and the ease of handling a single propellant during refueling and servicing operations make it attractive.

If the imagination is stretched to encompass propellant manufacture on the moon, a hydrogen-oxygen-nitrogen mixed gas system could be considered for more advanced hoppers. The authors don't feel qualified to discuss the probabilities for development of magnetic platforms or space coupes for lunar applications anytime in the future, in spite of Dick Tracy's success.

EARTH ORBIT MISSIONS - The area of earth orbital operations is often passed over in discussions of advanced propulsion requirements. A simile may be drawn between this neglect and the relative importance of supersonic or hypersonic transport aircraft to urban transportation problems. The question of "how can it be done" is well answered by existing technology. Interest in providing answers to "how can it be done better" is less evident. At least part of this apathy stems from the flatness of the cost curve (Figure 9) in this area.

Future missions of long duration in earth orbit, especially large manned stations, will require system total impulses the same order as the smaller instrumented deep space probes. The additional complexities of resupplying these auxiliary propulsion systems require consideration not normally given expendable systems. In fact, the back door to rocket system reusability is open in the earth orbital area. Planning for near term large systems such as the Apollo Applications S-IVB Laboratory (Figure 17) uniformly considers state of art earth storable liquid rocket systems like those in use

Ward W. Wilcox \& Robert H. Rollins, II

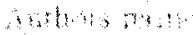


on the Apollo spacecraft. These

systems, by and large, are not designed

for refueling and rely on limited cycle-

life expulsion devices for propellant

feed.

There will be many requirements

for improved propulsion capabilities

for the large orbital stations as their

complexity increases (Figure 18).

Other possible manned orbital operations

lie in the area of assembly of separate-

ly launched payloads for escape missions

repair or retrieval of existing space-

craft, and rescue missions. In each

of these areas, small maneuverable

extravehicular propulsion systems

are necessary. The state of art has moved from oxygen gas jets used on

Gemini to the Hydrazine Hand-Held

Maneuvering Unit shown in Figure 19.

The family of maneuvering units

(AMU, RMU, MMU) under development in

connection with the MOL project is

the next step. Proposals for space

tugs or tractors lie in the future.

In smaller orbital spacecraft,

long life systems for the simple

propulsion requirements will be required

to match the state of art improvements

in the other satellite subsystems. The long time storability of monopropellant hydrazine makes it a very attractive candidate for near term developments. Electrically based systems will become more attractive as advanced power sources evolve.

SUMMARY

In summary, it is obvious that the void of space is full of interesting things to do. In the main we have the propulsion capability to do these things, or at least a basis of technology which gives us confidence they can be done. When it comes down to the hard choices of specific pieces of hardware required to do well defined jobs in a specific way, a lot of work

Ward w. Wilcox \& Robert H. Rollins, II $1 \overline{7}$ 
remains to be bone. It will require careful analysis and good engineering judgement to pick a winner from all the possible modes of propulsion. While such selections are tough jobs, they are not impossible jobs and can be handled in a straightforward manner. Trying to establish a really complete technology base without duplication or waste, seems to be a more elusive activity. Until the time comes for selection of specific propulsion units, however, the effort to improve the level of knowledge in propulsion is an investment which will pay off handsomely in the future.

Ward W. Wilcox \& Robert H. Rollins (A) 18 
Table I - Space Propulsion Environment

Table II - Propulsion Performance Parameters

Table III - Unmanned Planetary Missions

Table IV - Synchronous Equatorial Orbit Missions

Fig. 1-Trip Time for Planetary Orbit Missions

Fig. 2 - Thermal Spectrum for Spacecraft Propulsion

Fig. 3 - Gemini Spacecraft Propulsion

Fig. 4 - Space Propulsion Performance Spectrum

Fig. 5 - Performance Characteristics of Some Typical Propellant Combinations

Fig. 6 - Comparison of Propellant Iiquid Ranges

Fig. 7 - Stage Volume Comparison

Fig. 8 - Spacecraft Sterilization

Fig. 9 - Mission Transportation Cost

Fig. 10 - Planetary Flyby Spacecraft

Fig. 11 - Typical Trajectory Profile

Fig. 12- Mars Orbiter Spacecraft

Fig. 13 - Mars Surface Sample Return Mission Profile

Fig. 14 - Mars Surface Sample Return

Fig. 15 - Lunar Logistics Vehicle Concept

Fig. 16 - Lunar Flying Unit

Fig. 17 - Orbital Workshop

Fig. 18 - Orbital Configuration

Fig. 19 - Hydrazine Hand-Held Maneuvering 


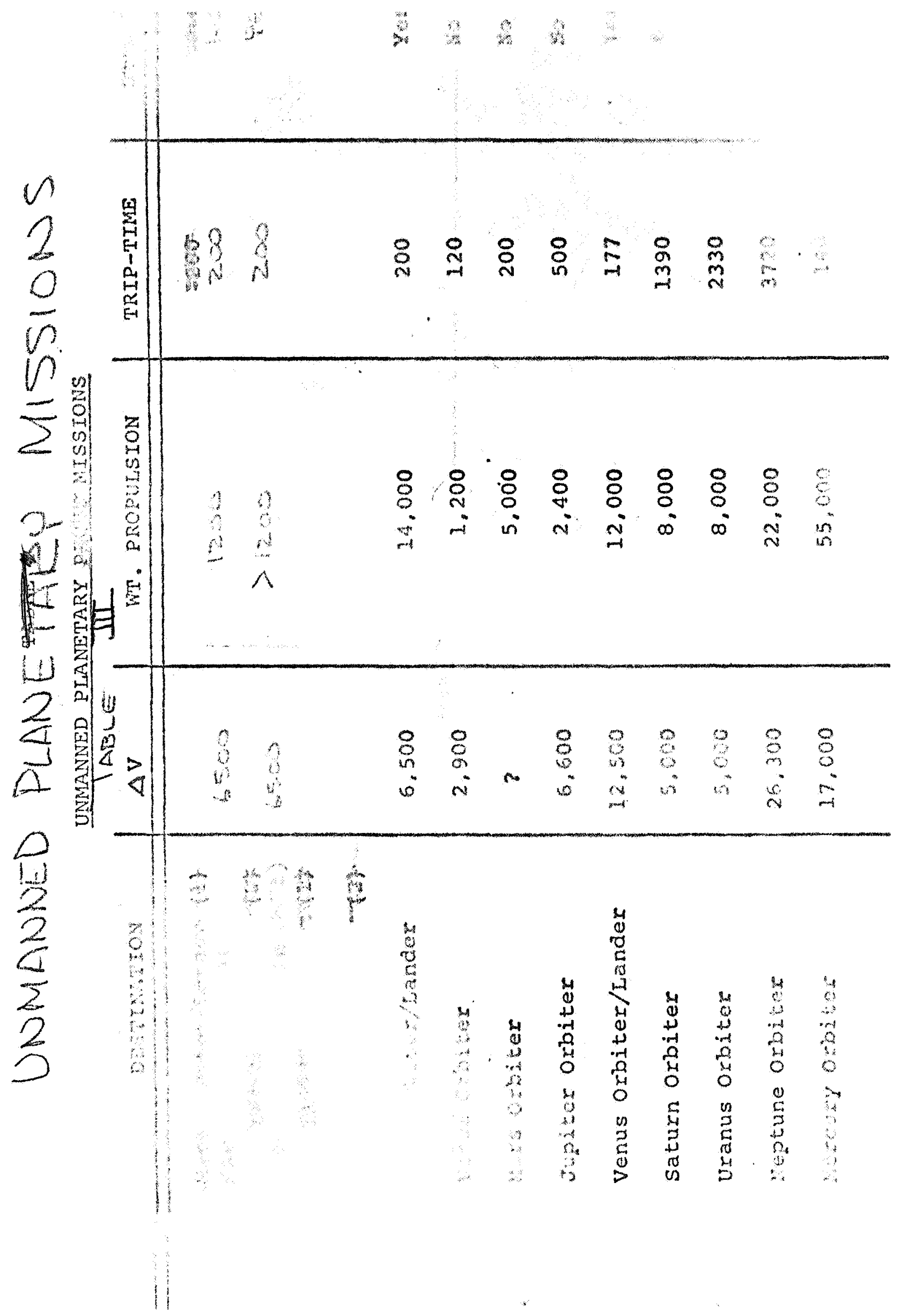




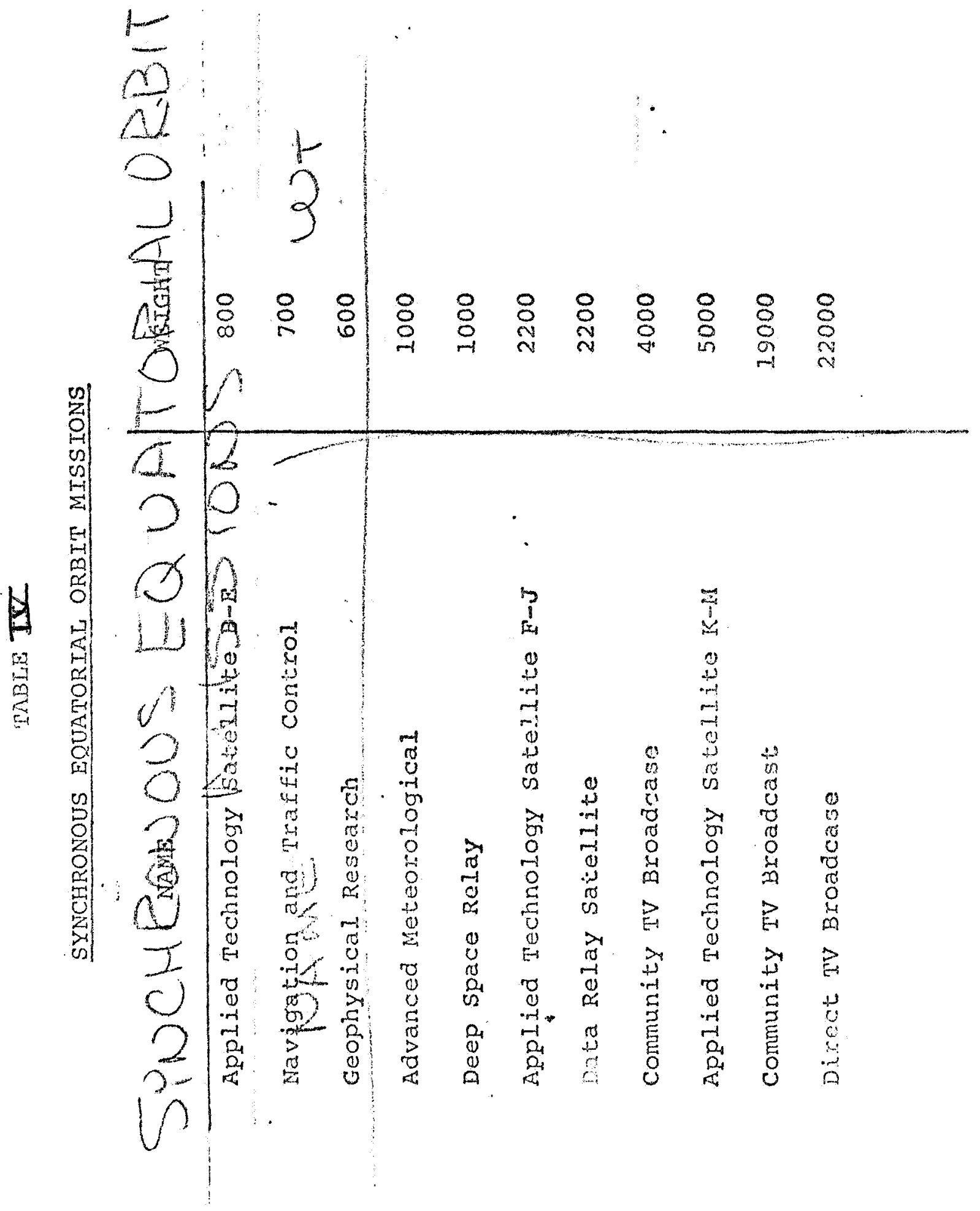




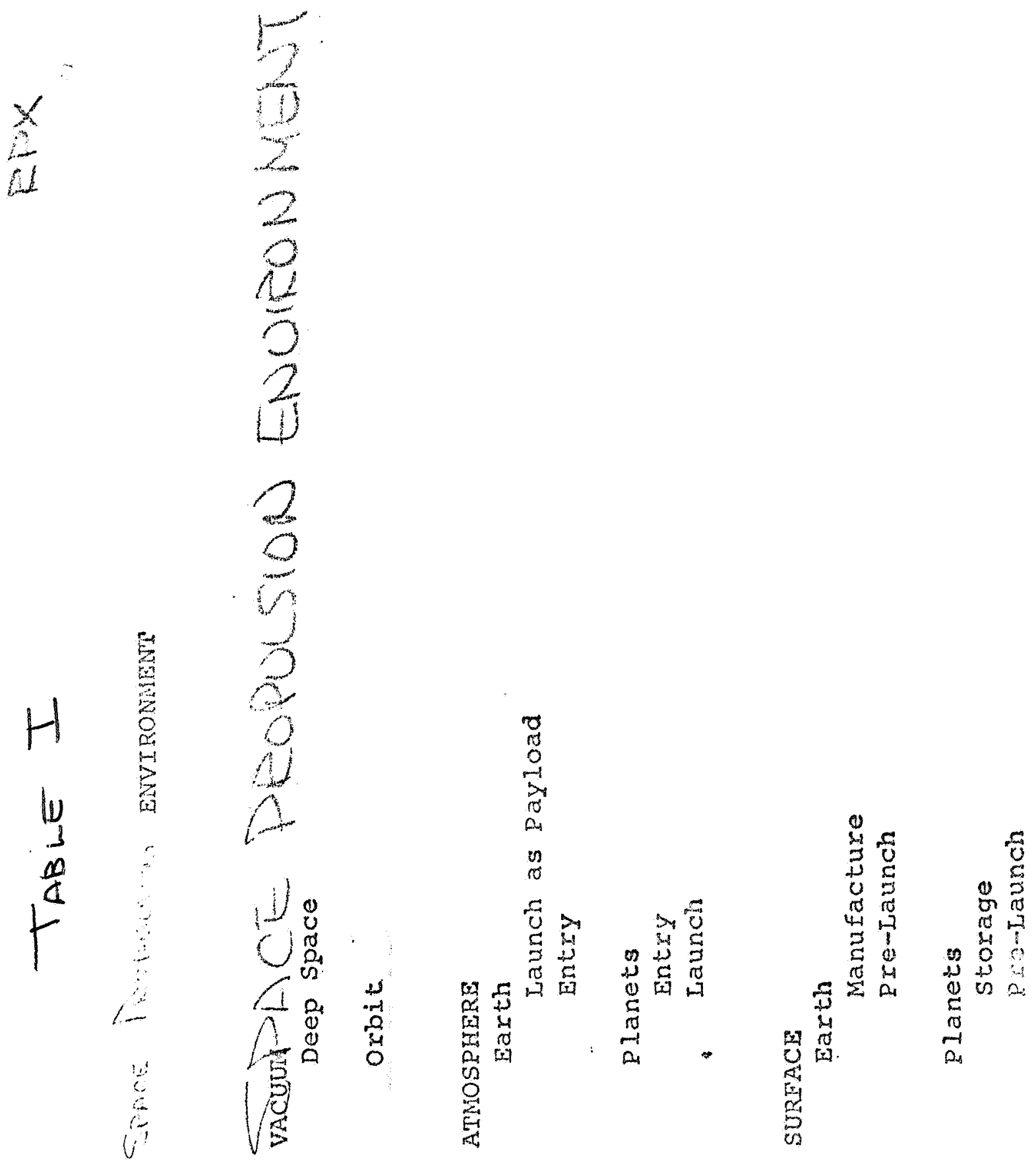




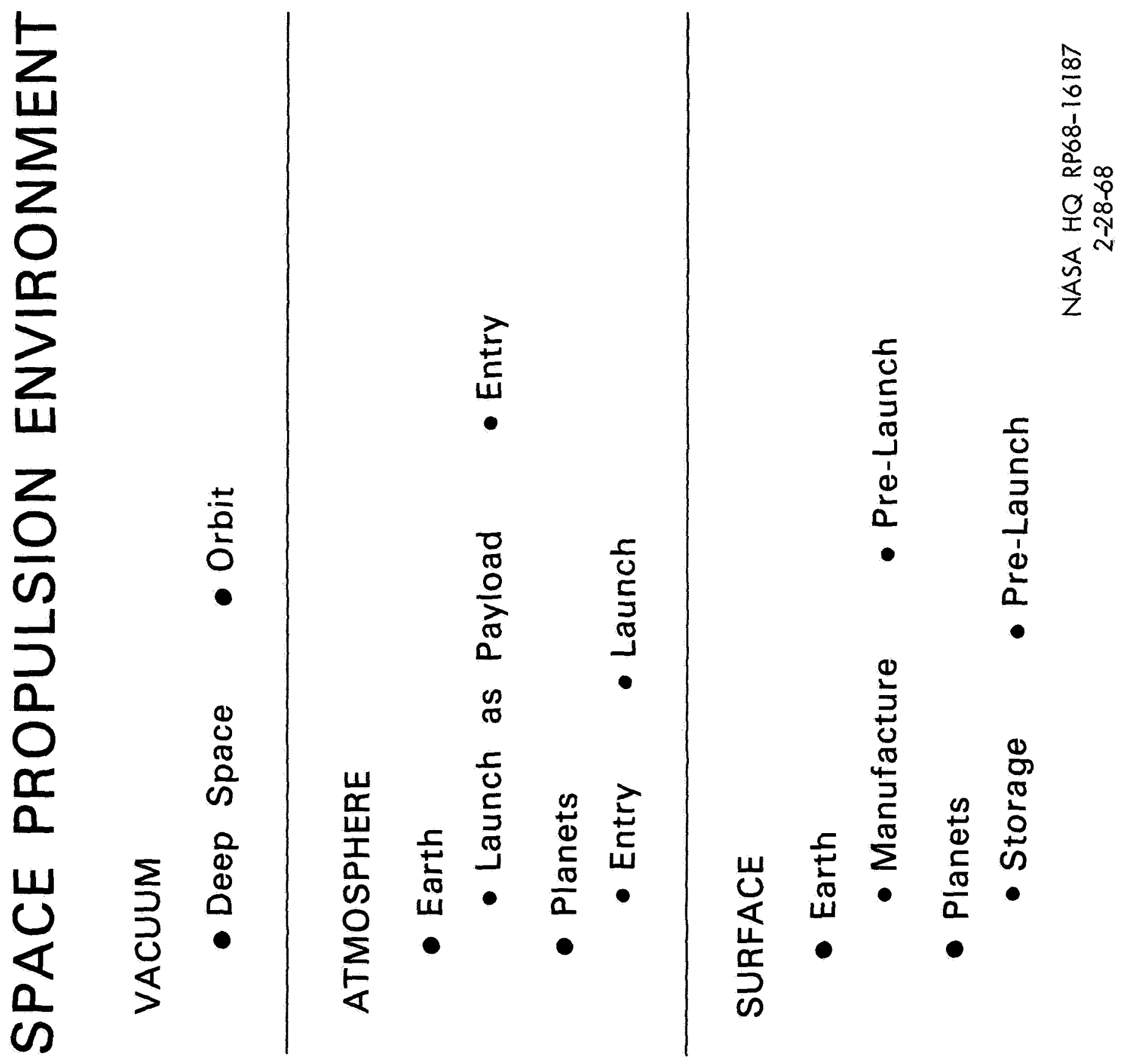




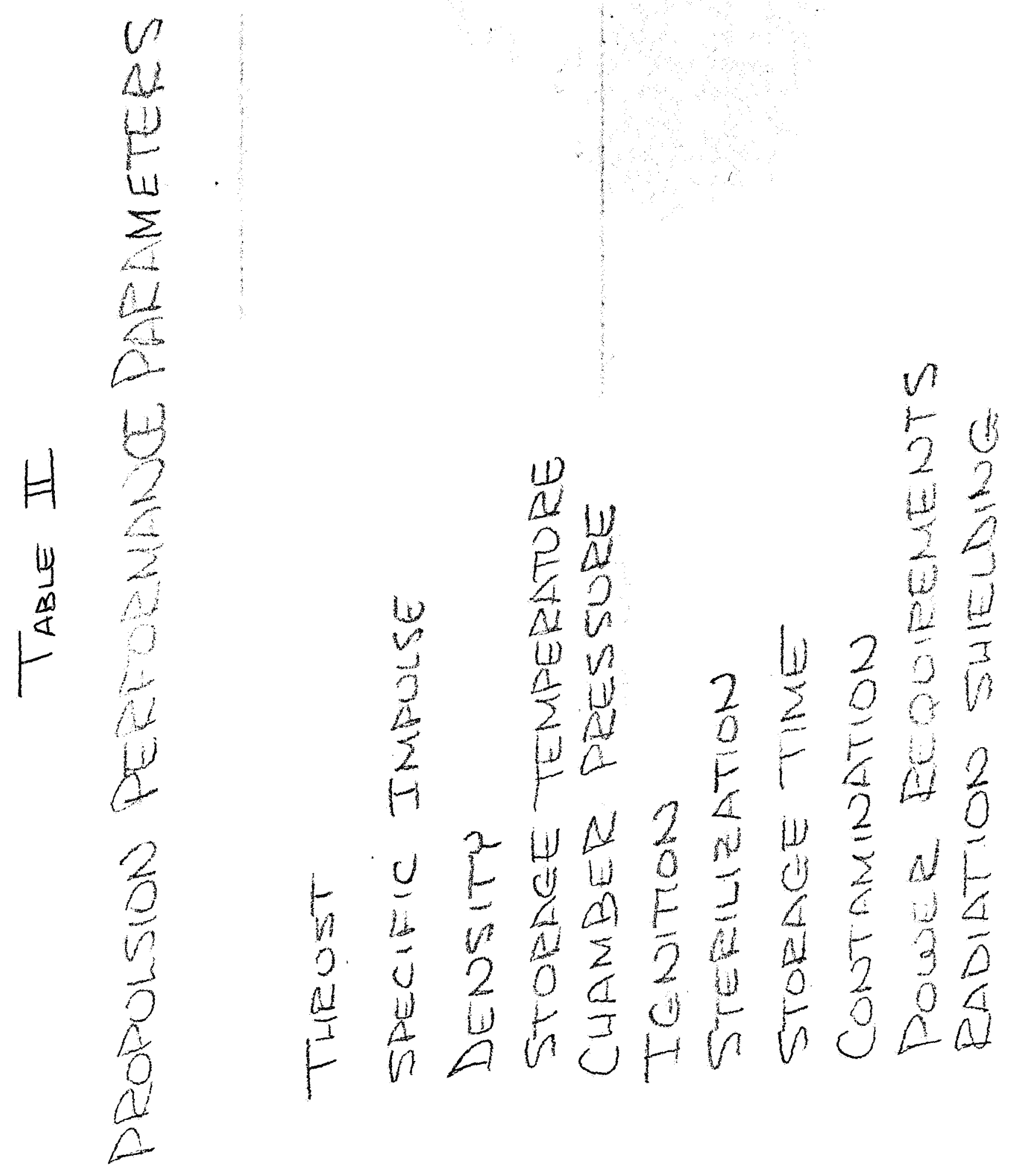




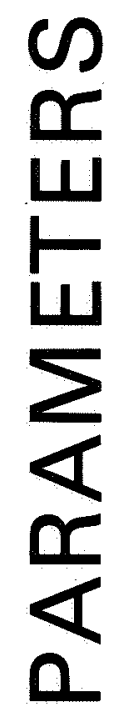

ш

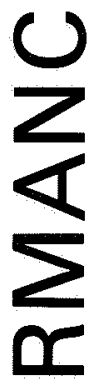

0

노

ш

w

w

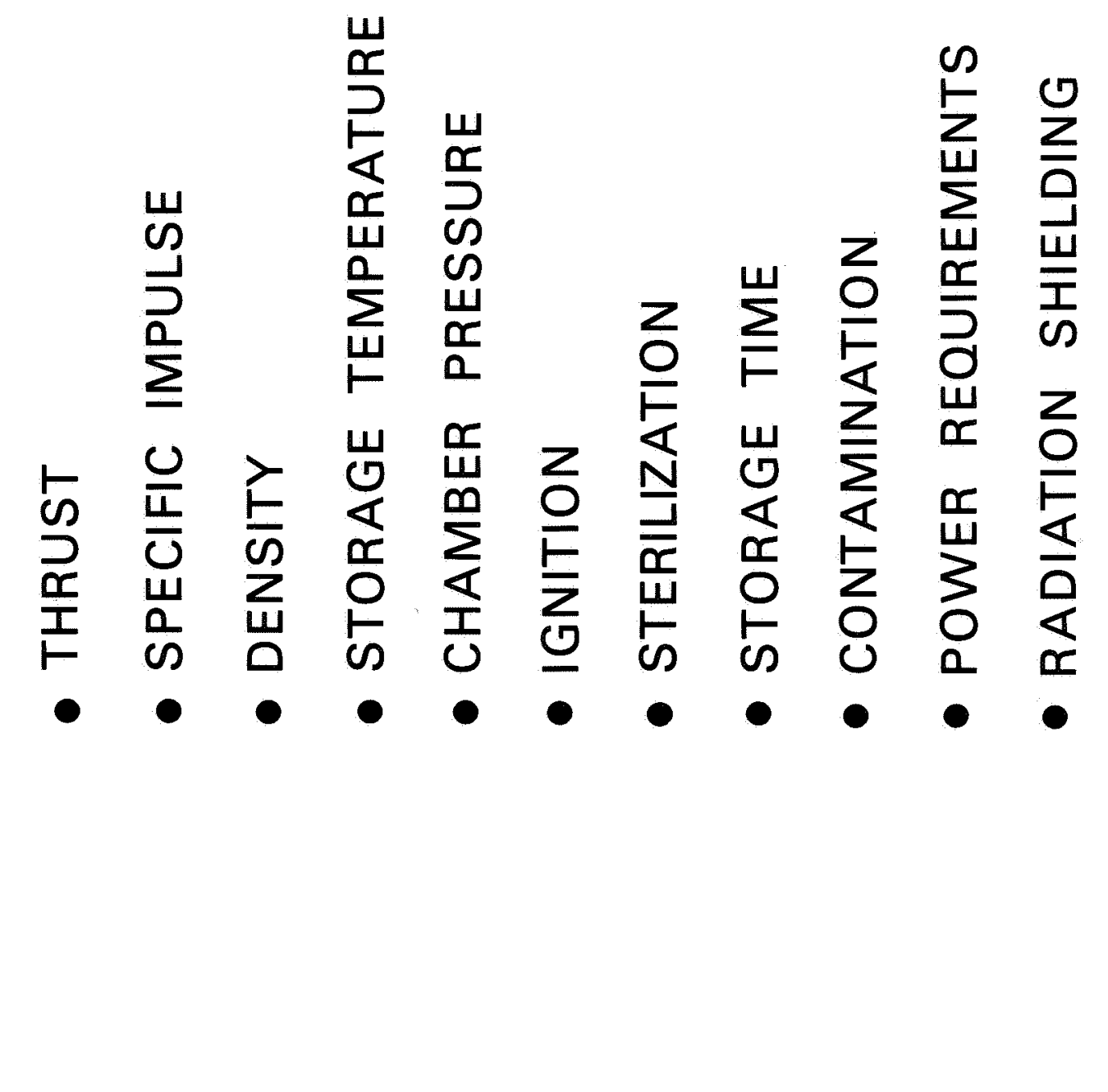

口

$z$
$\frac{2}{0}$
3
0
0
0
0
0 


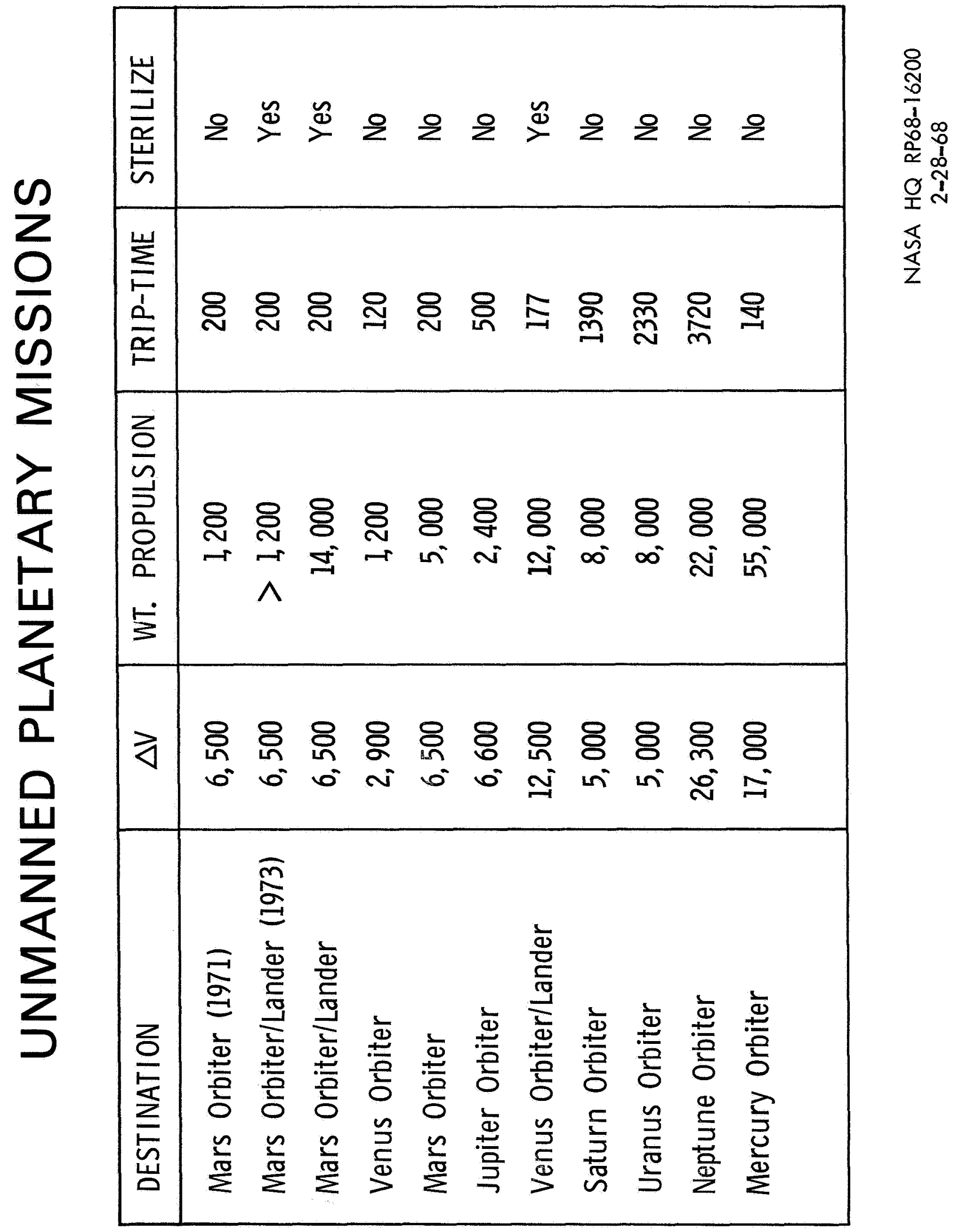




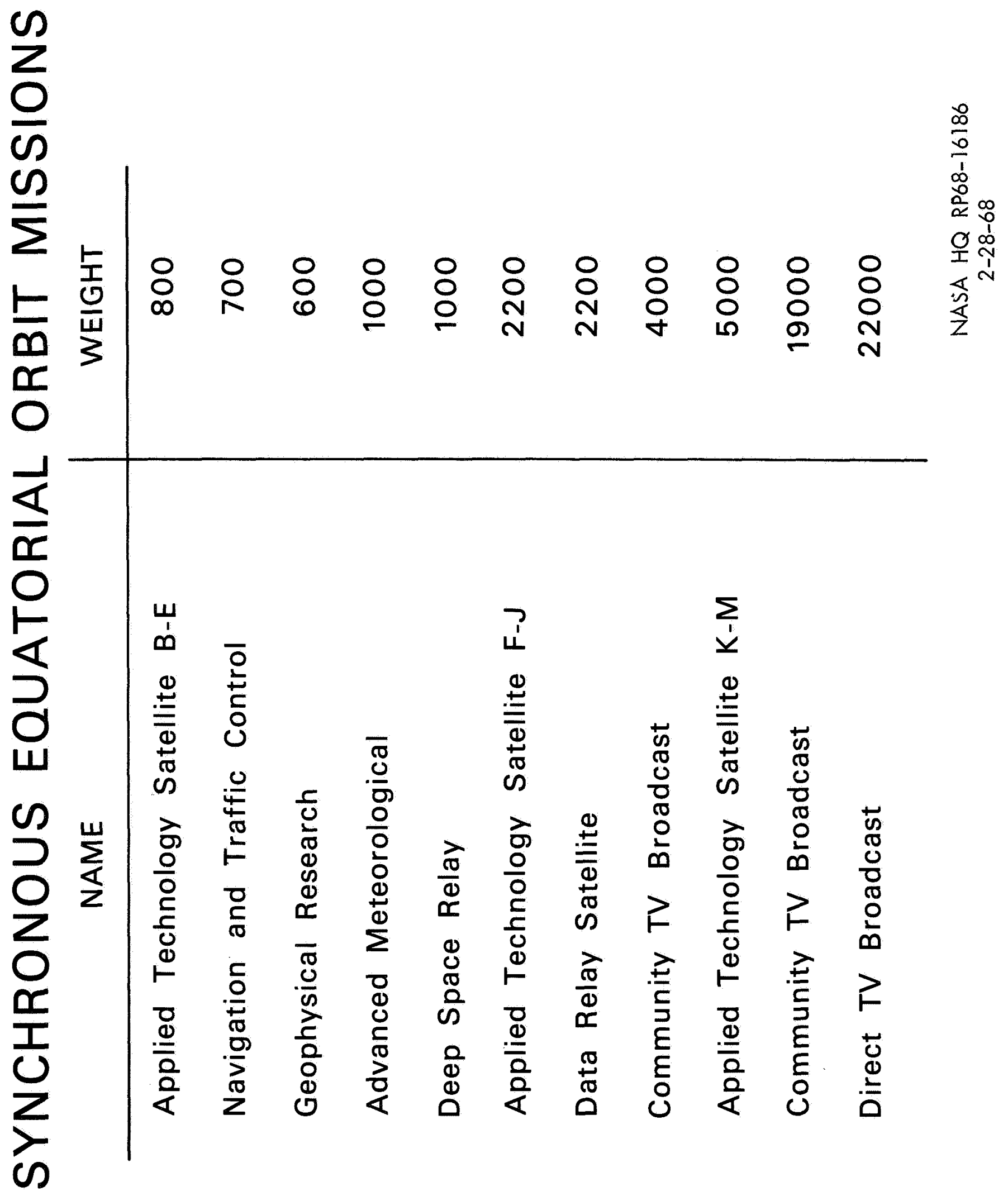




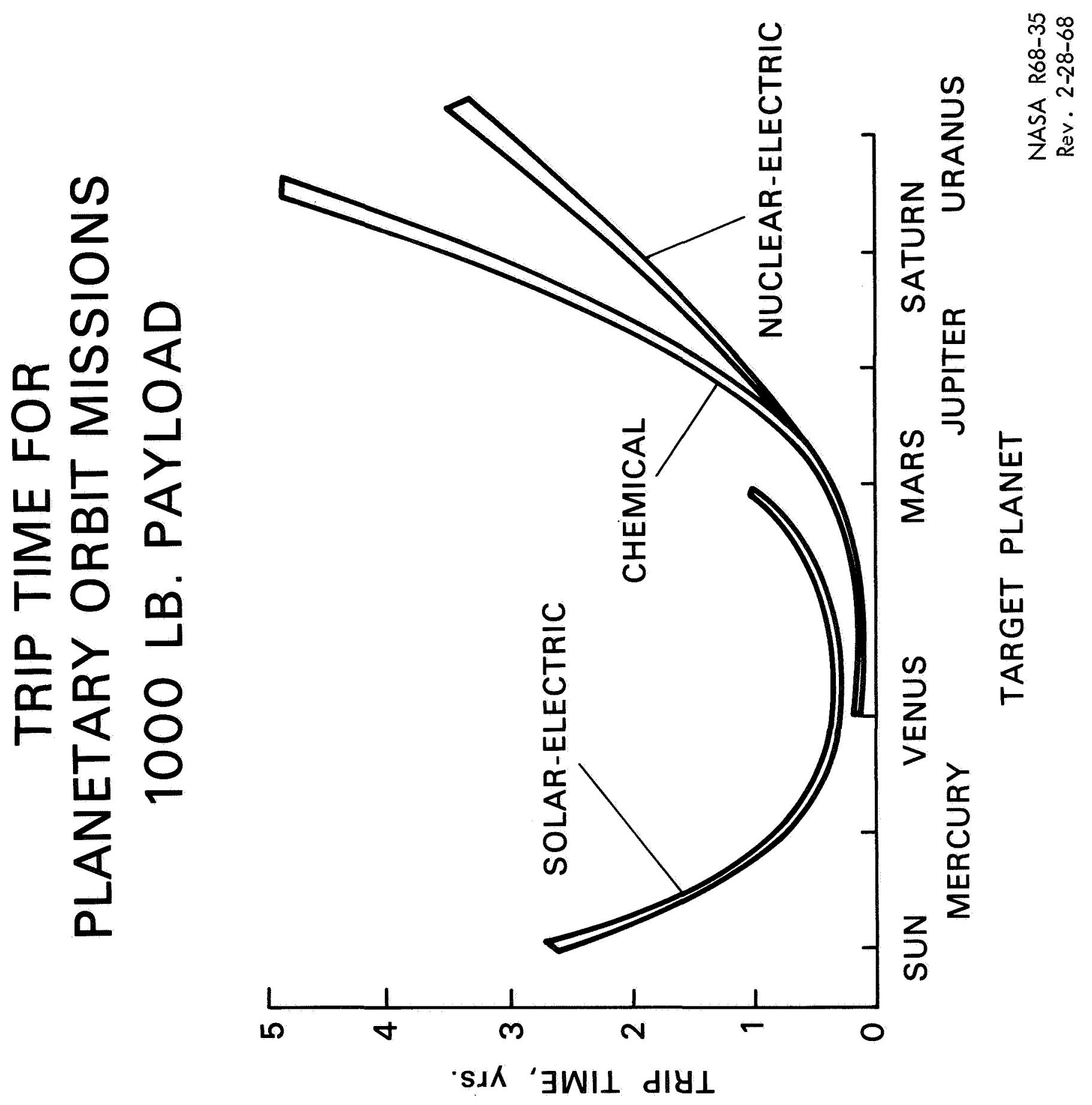




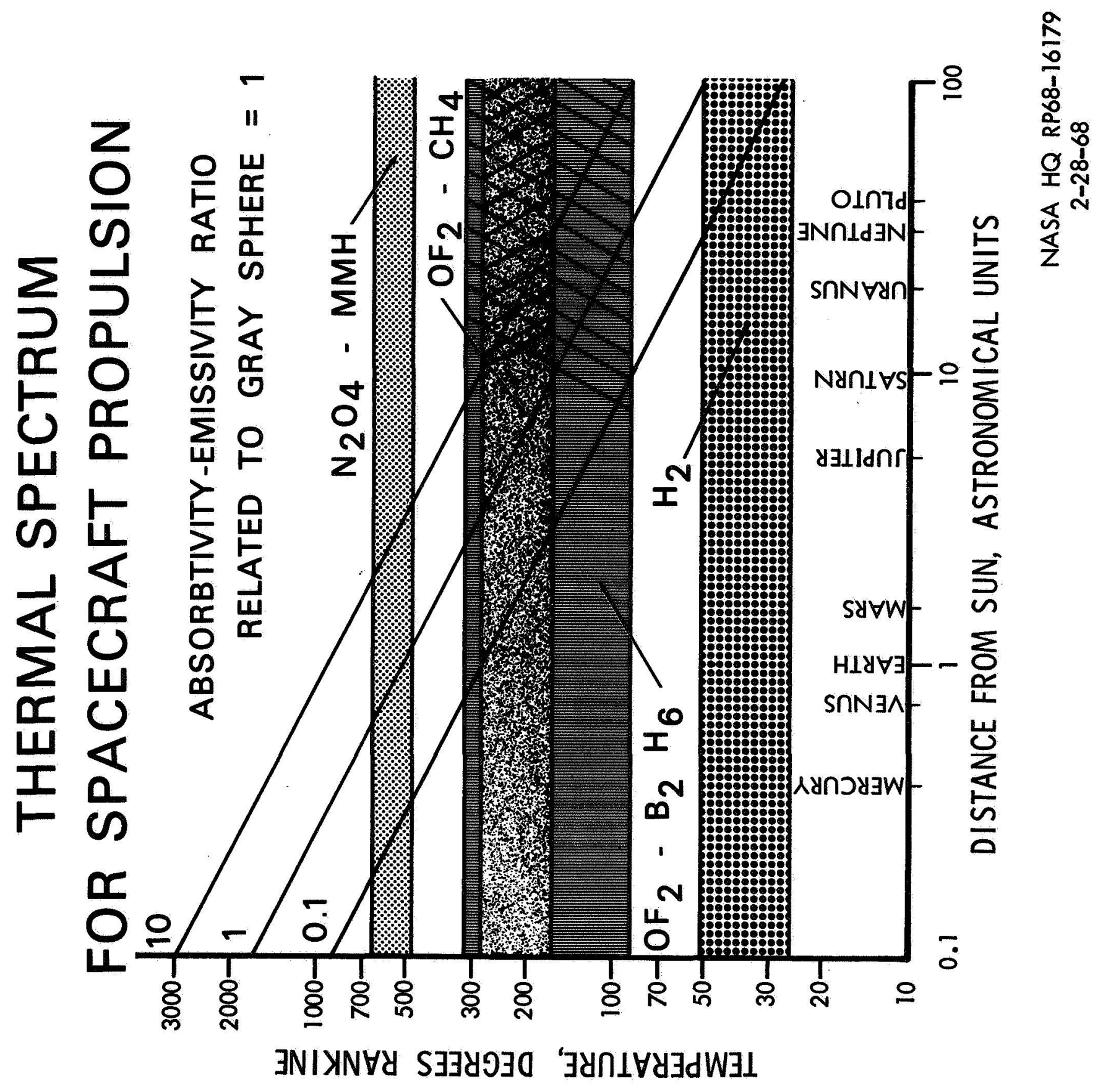




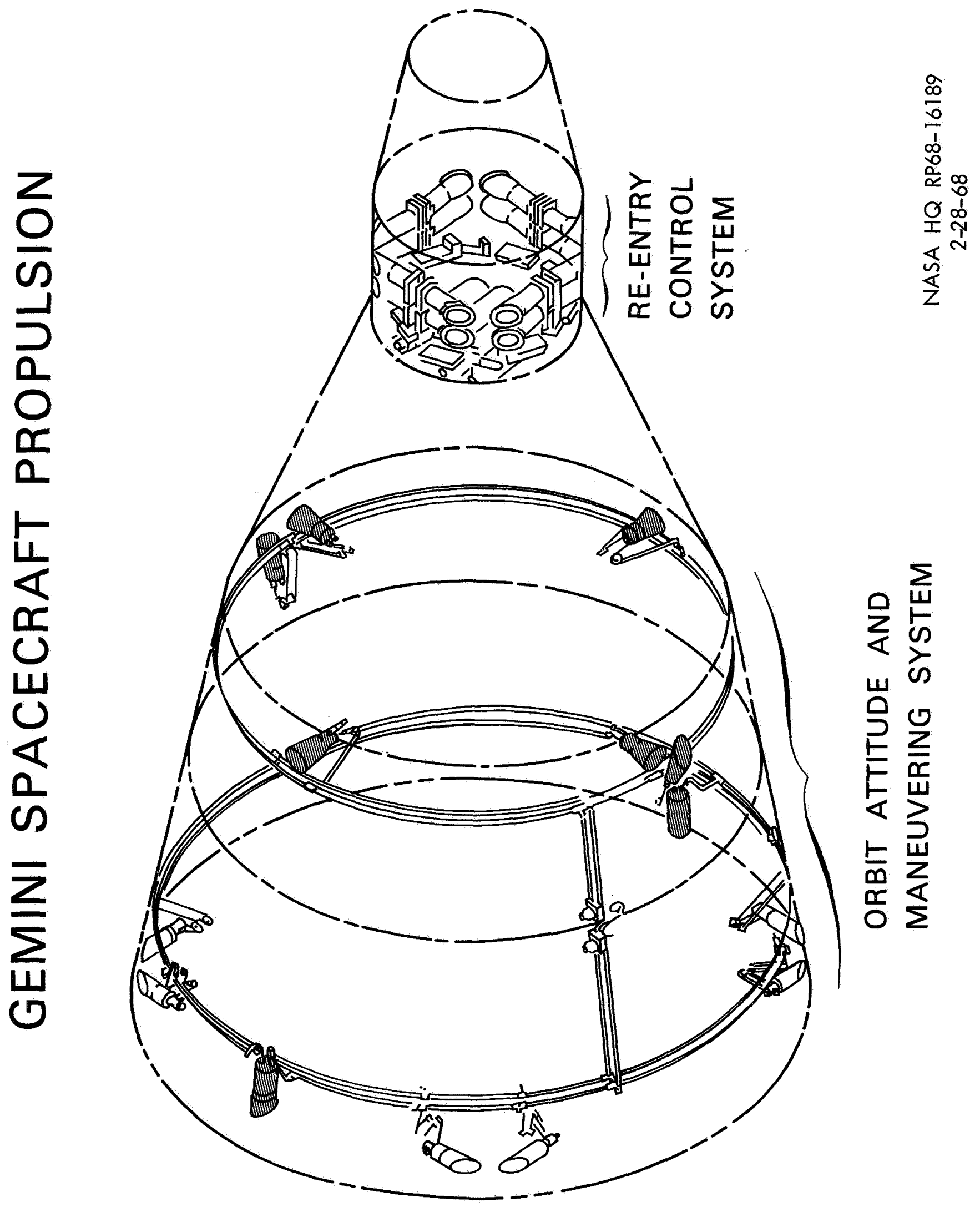




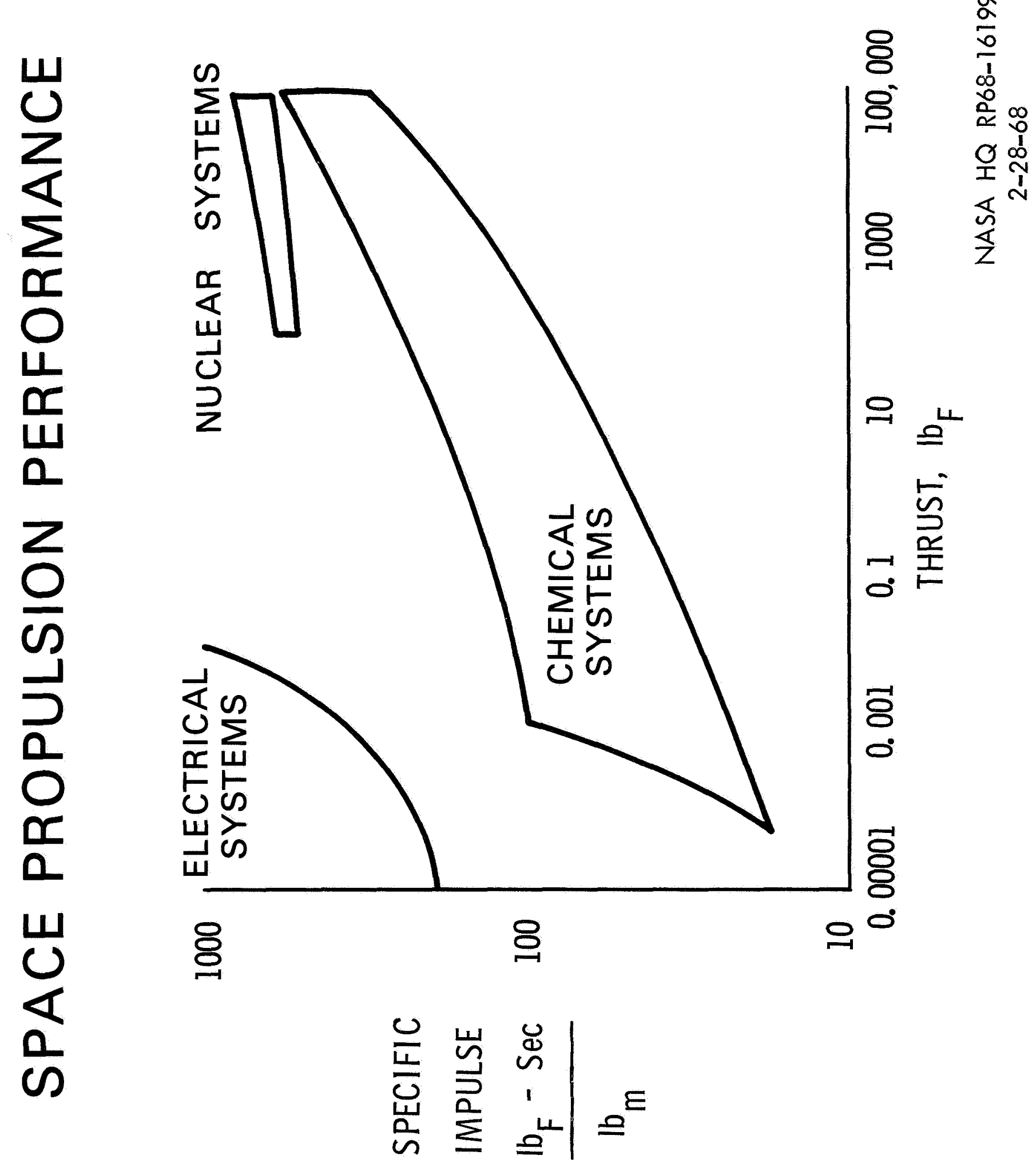




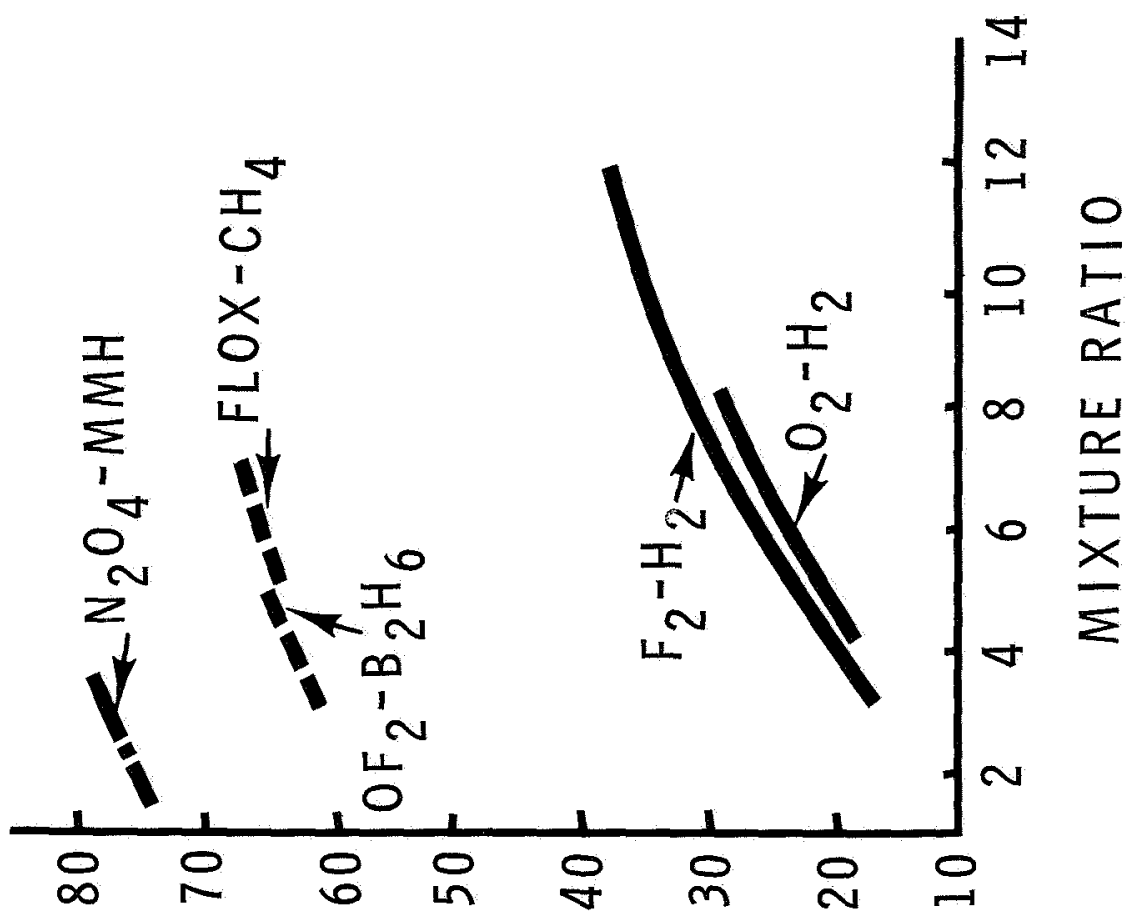

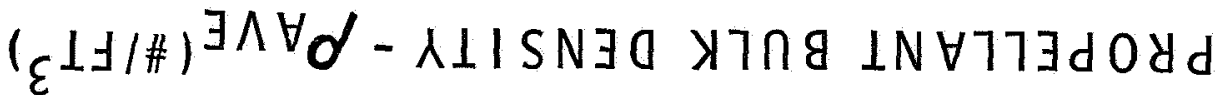

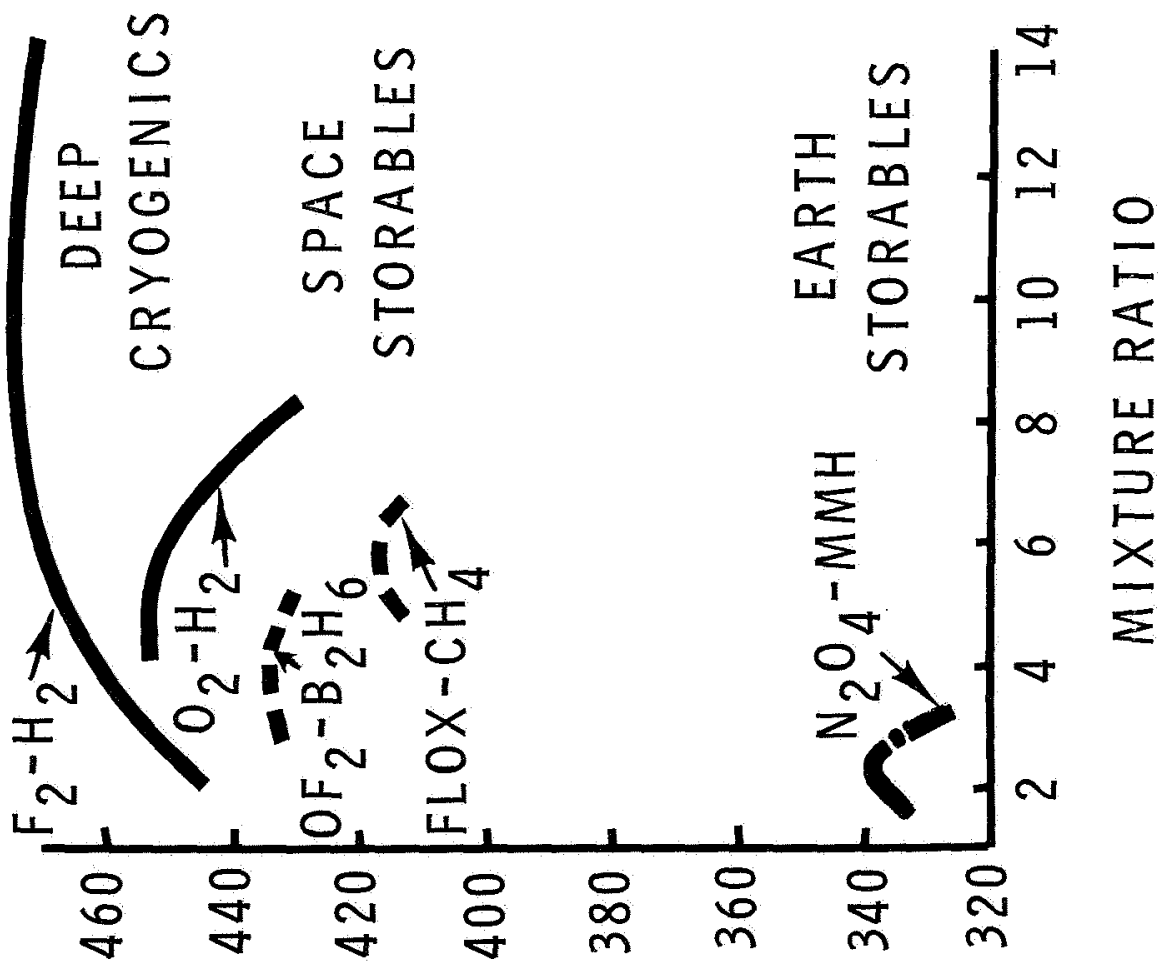

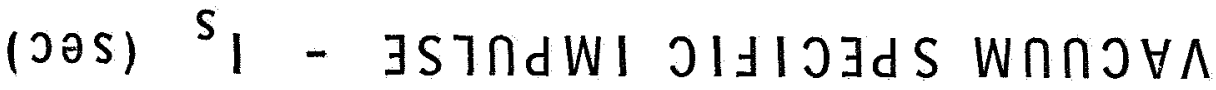




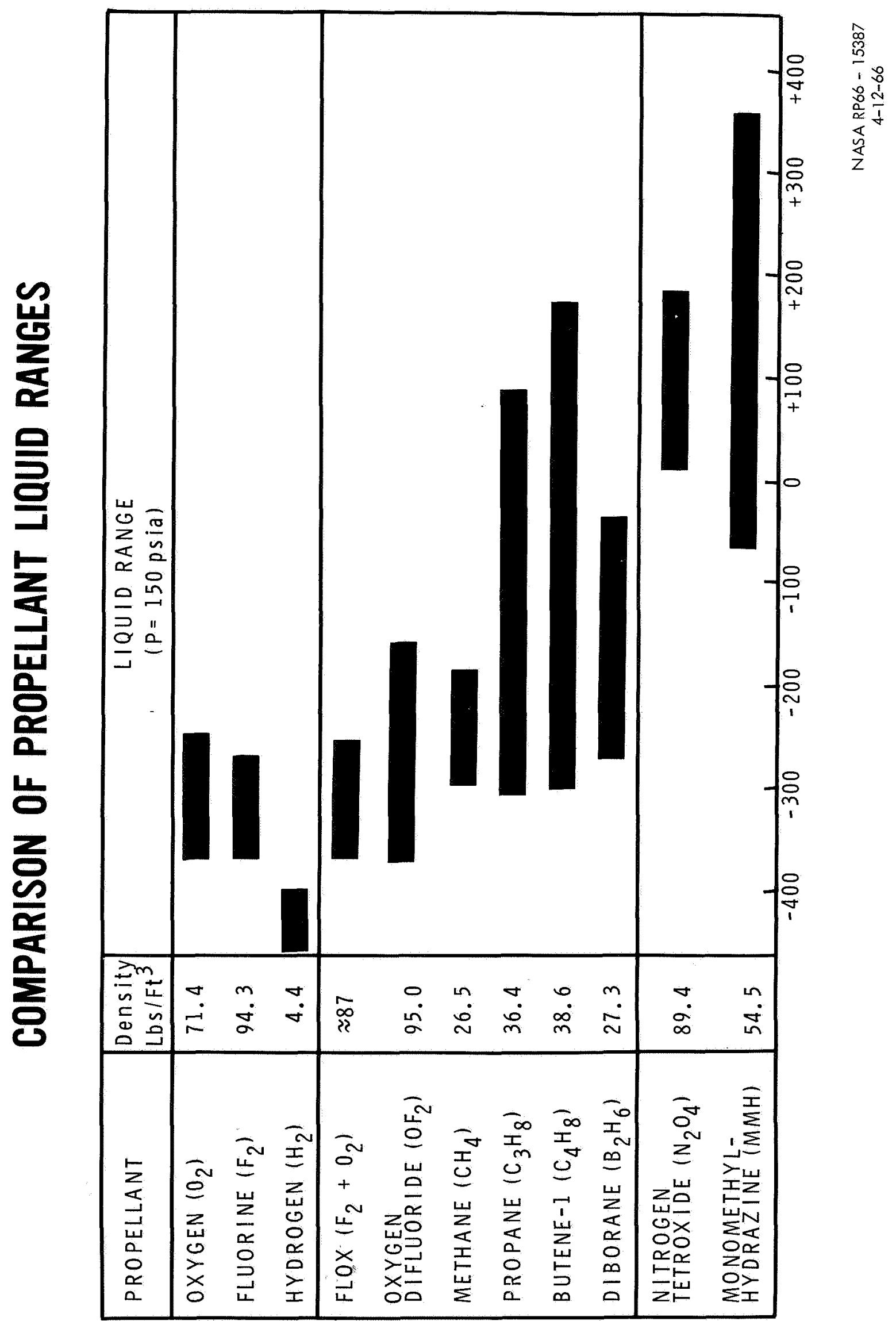




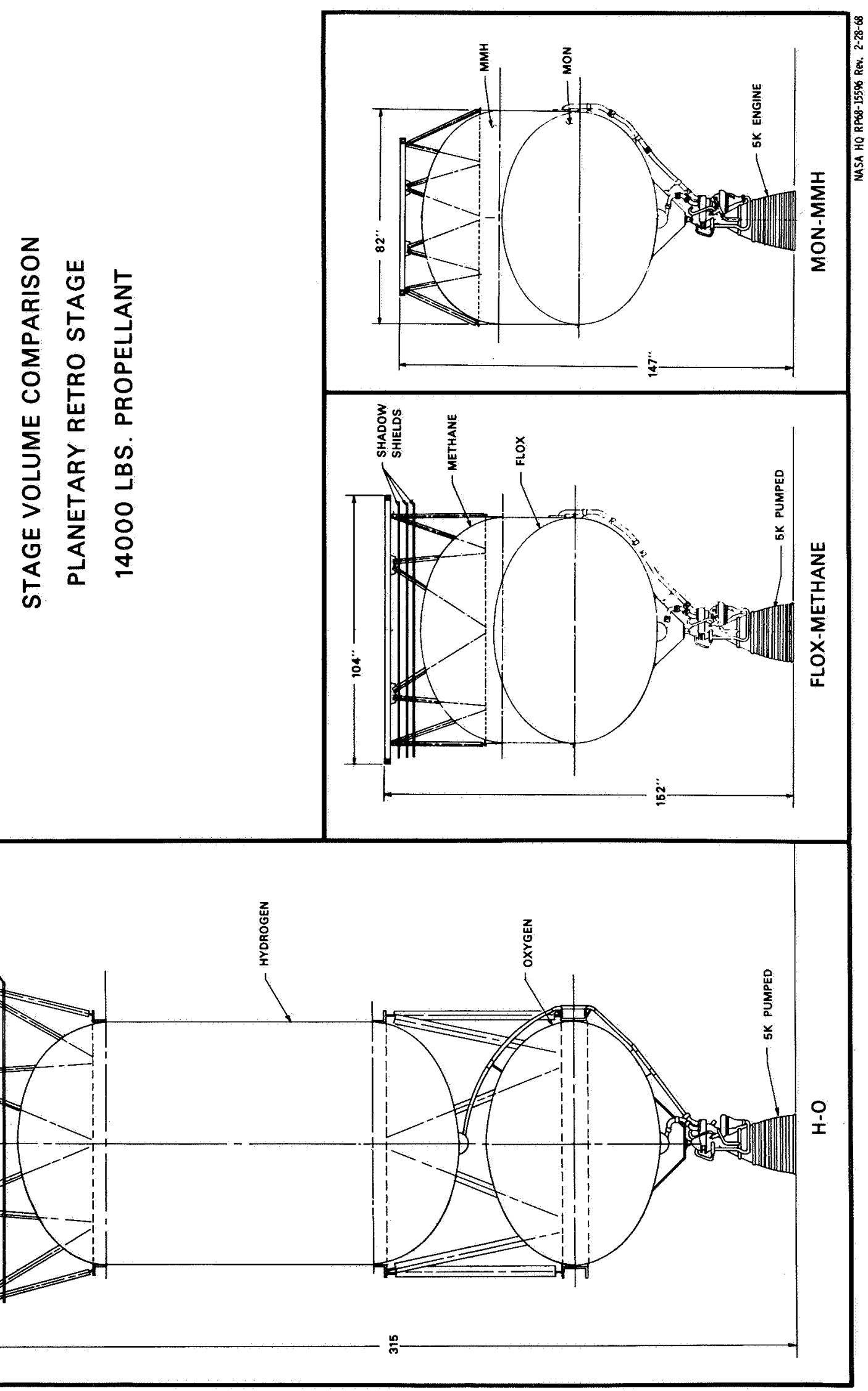




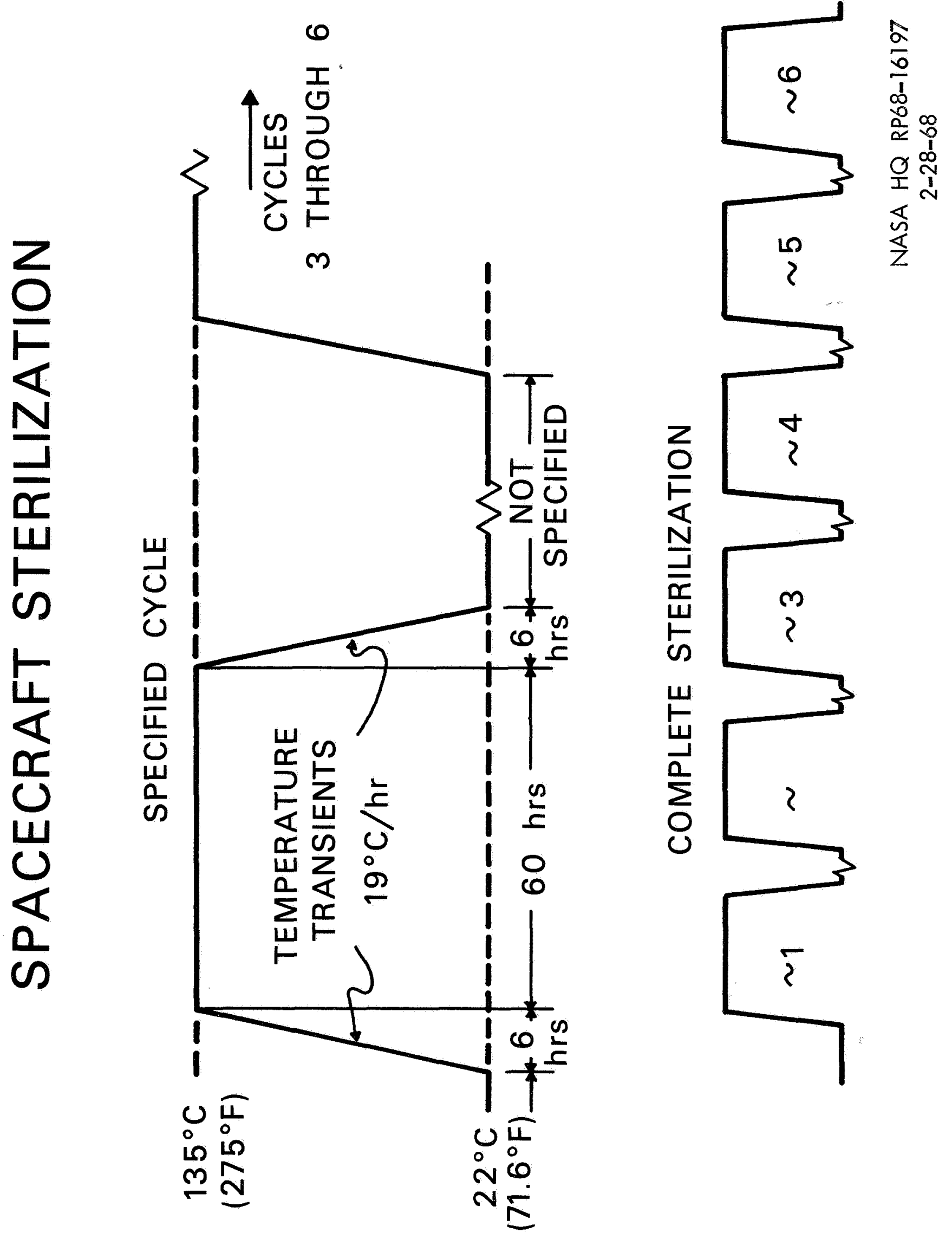




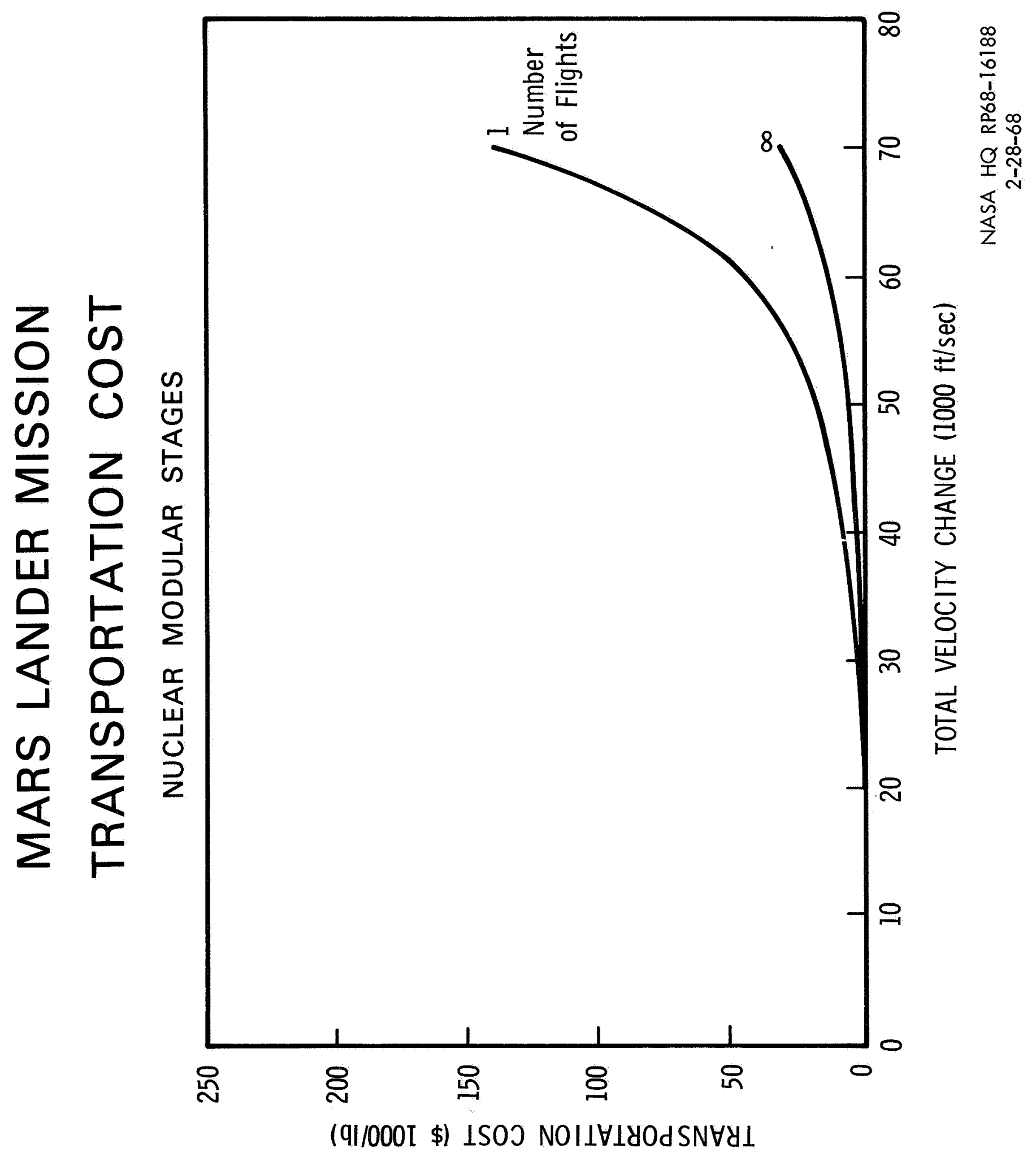




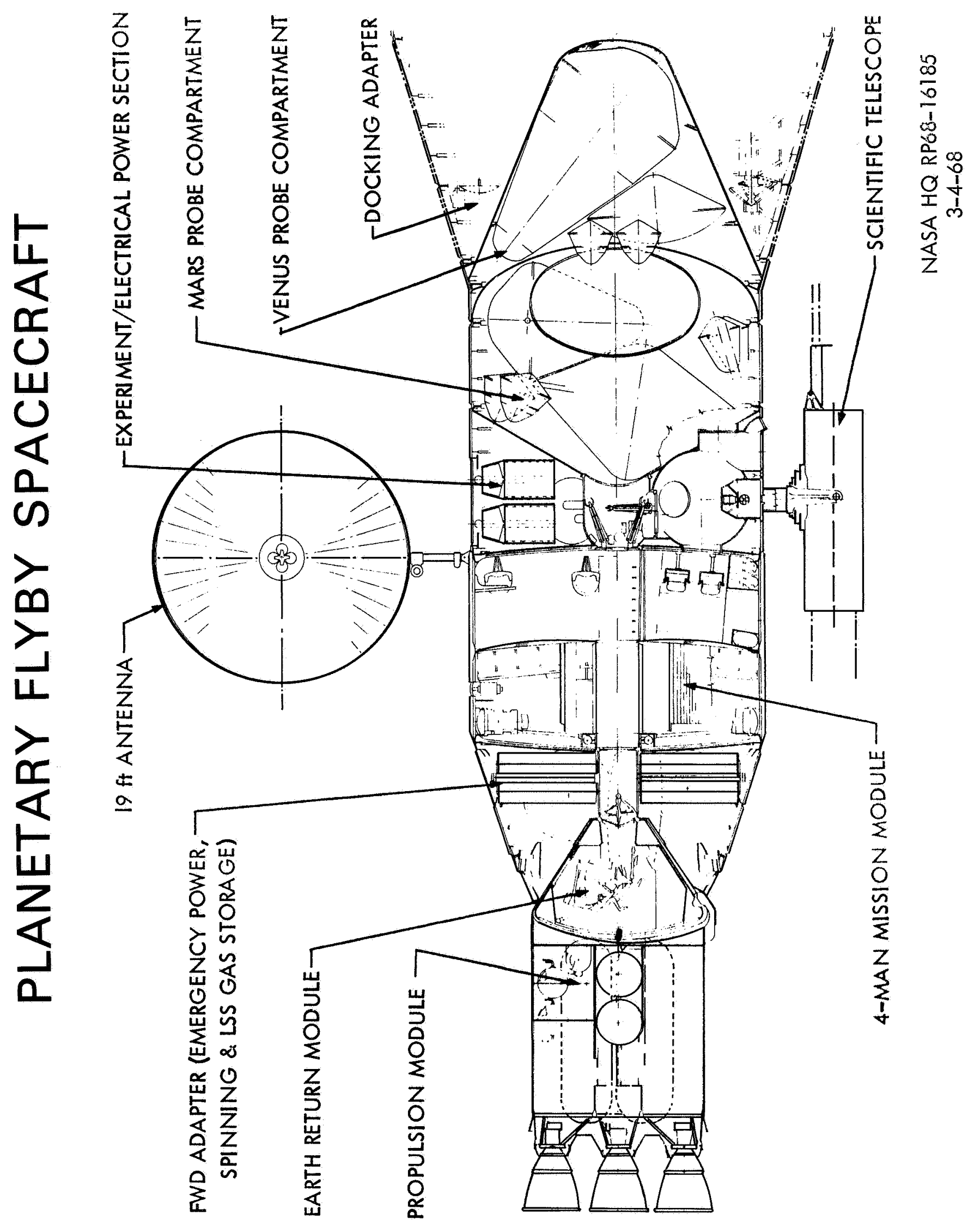




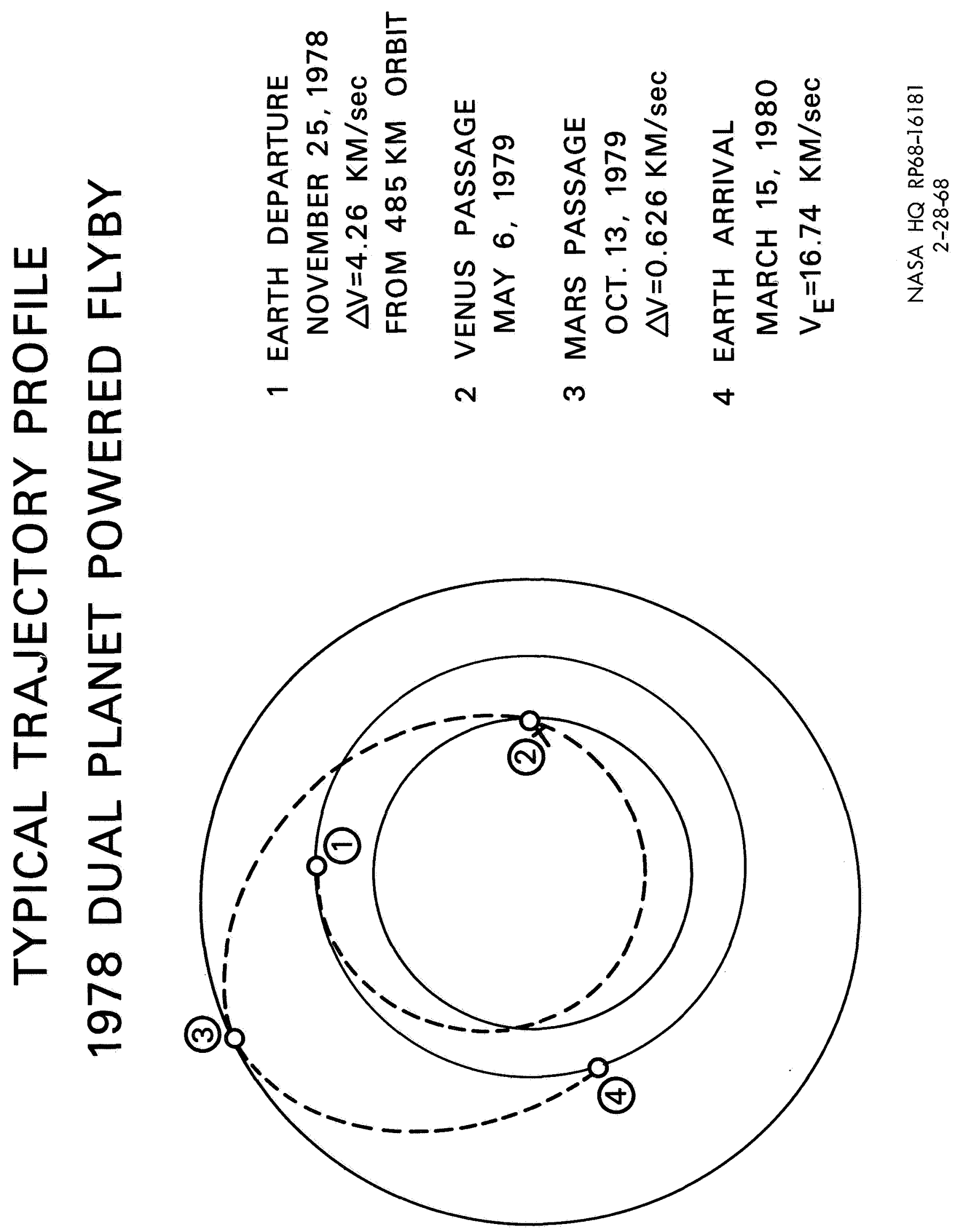




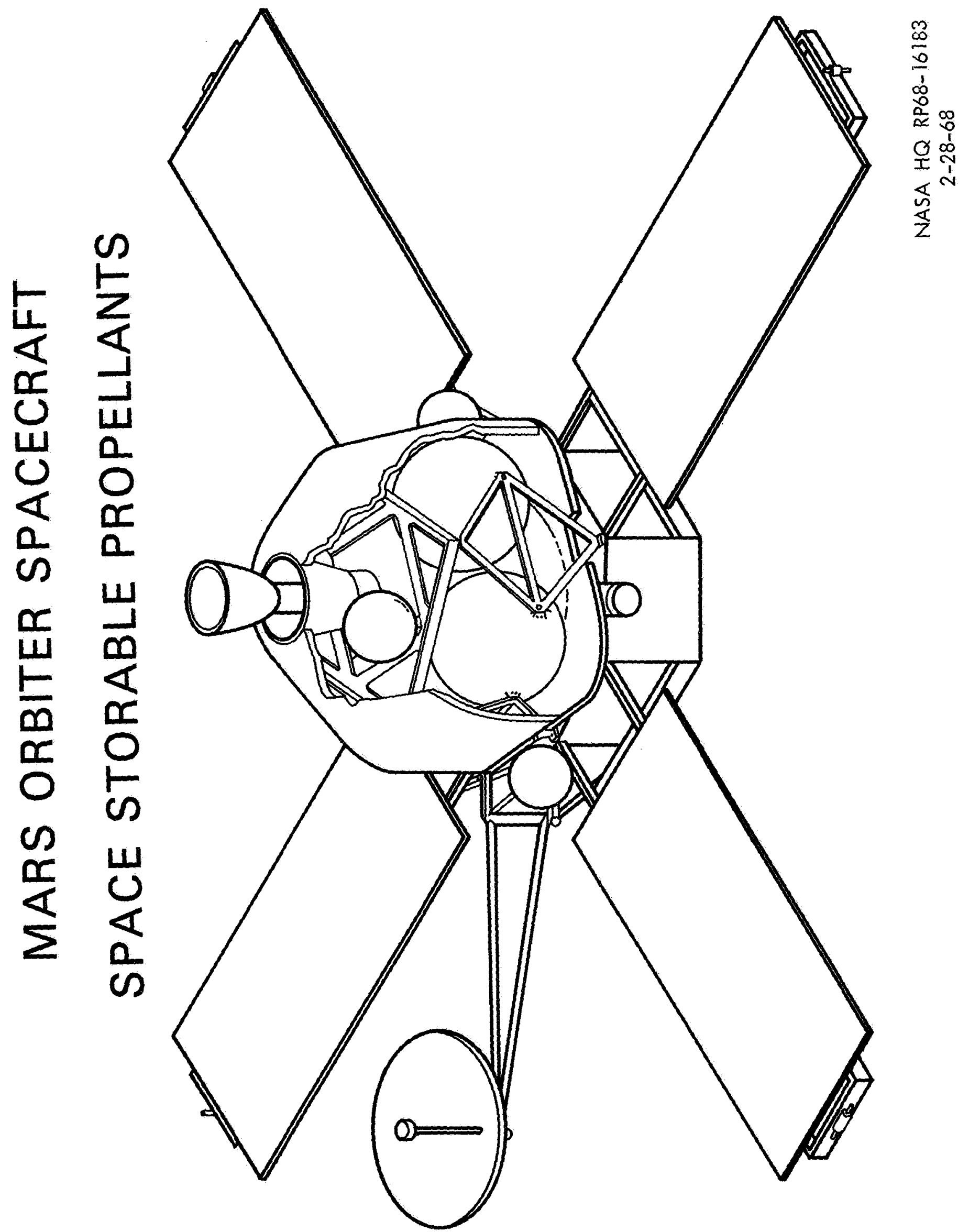




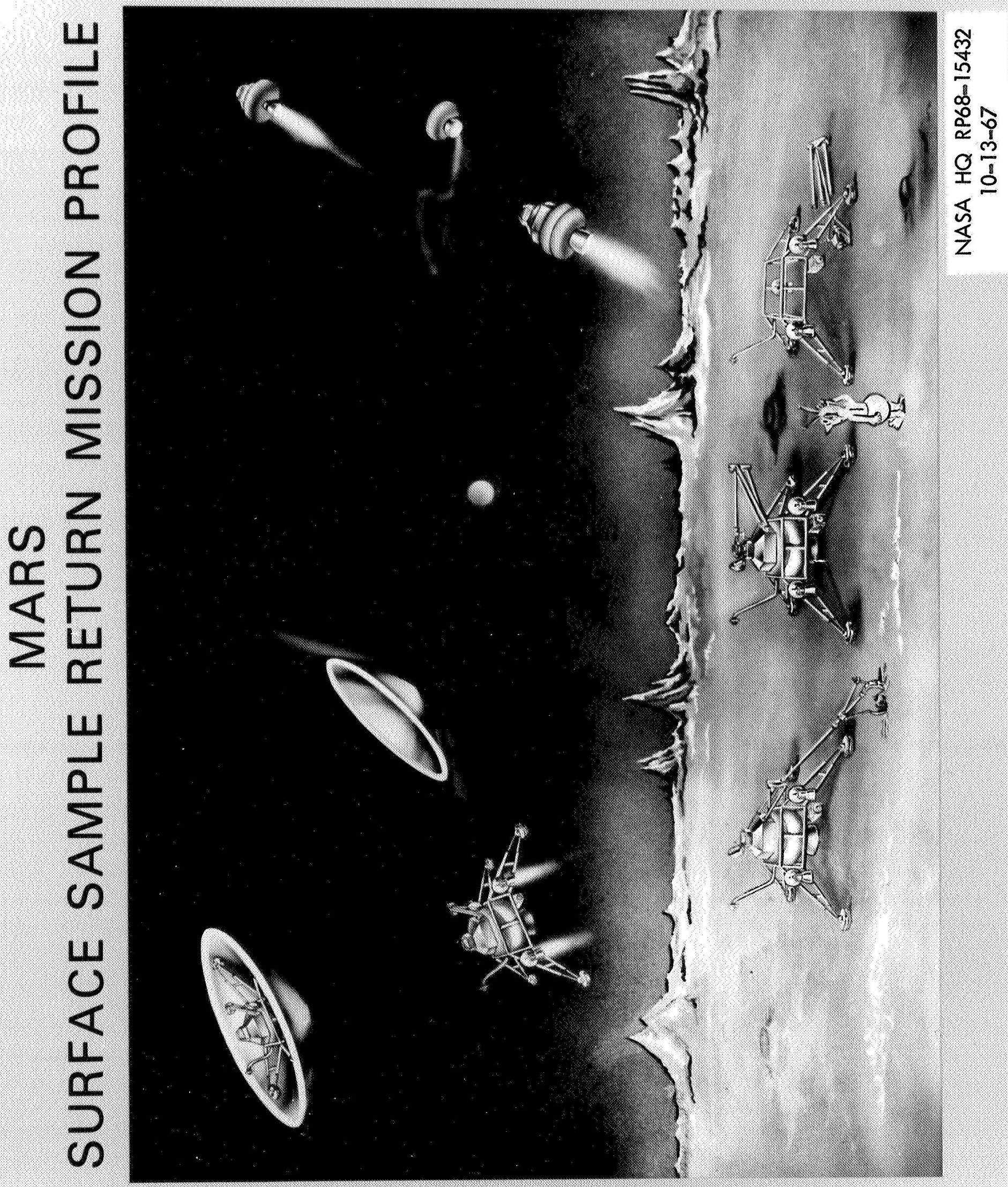



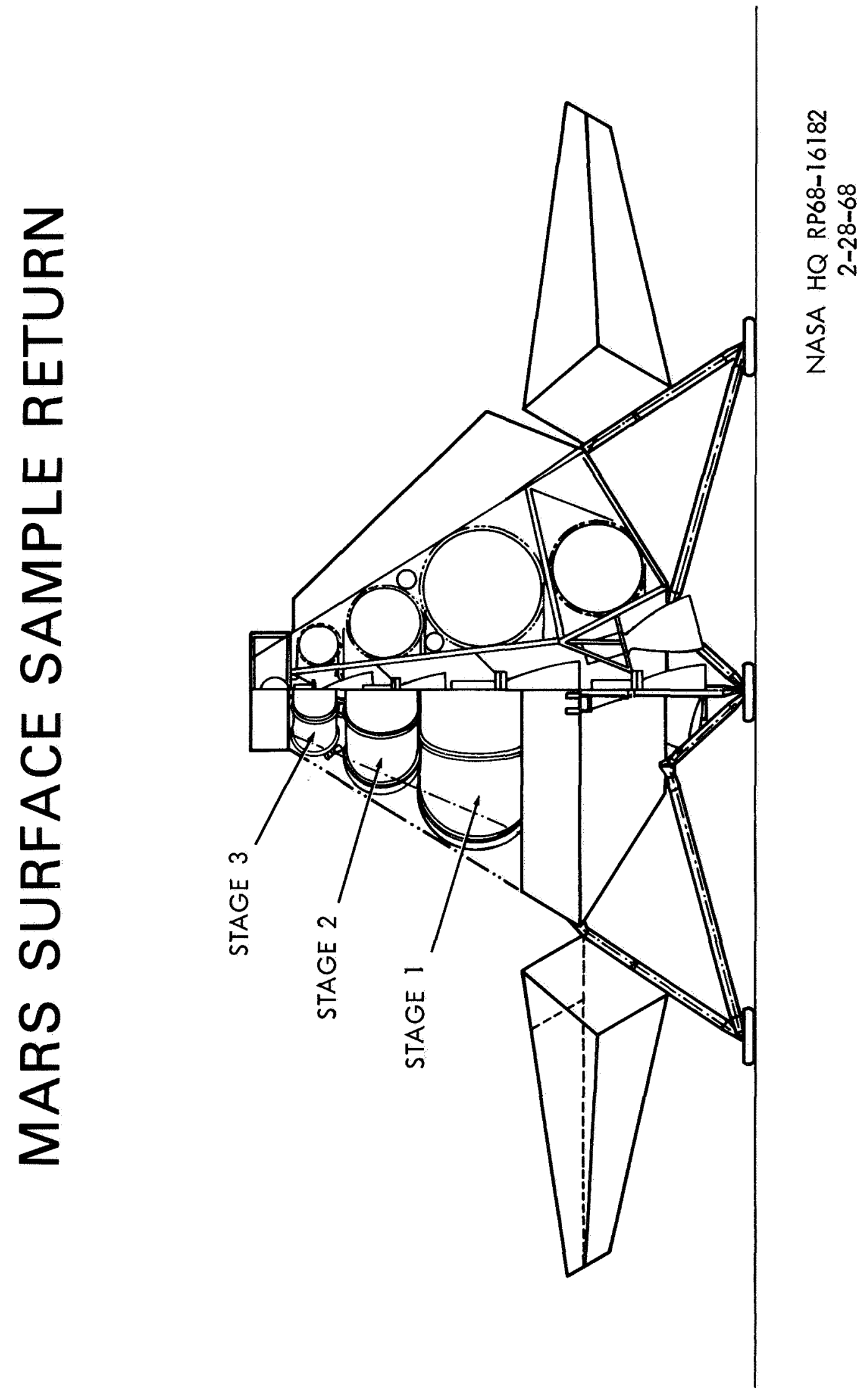


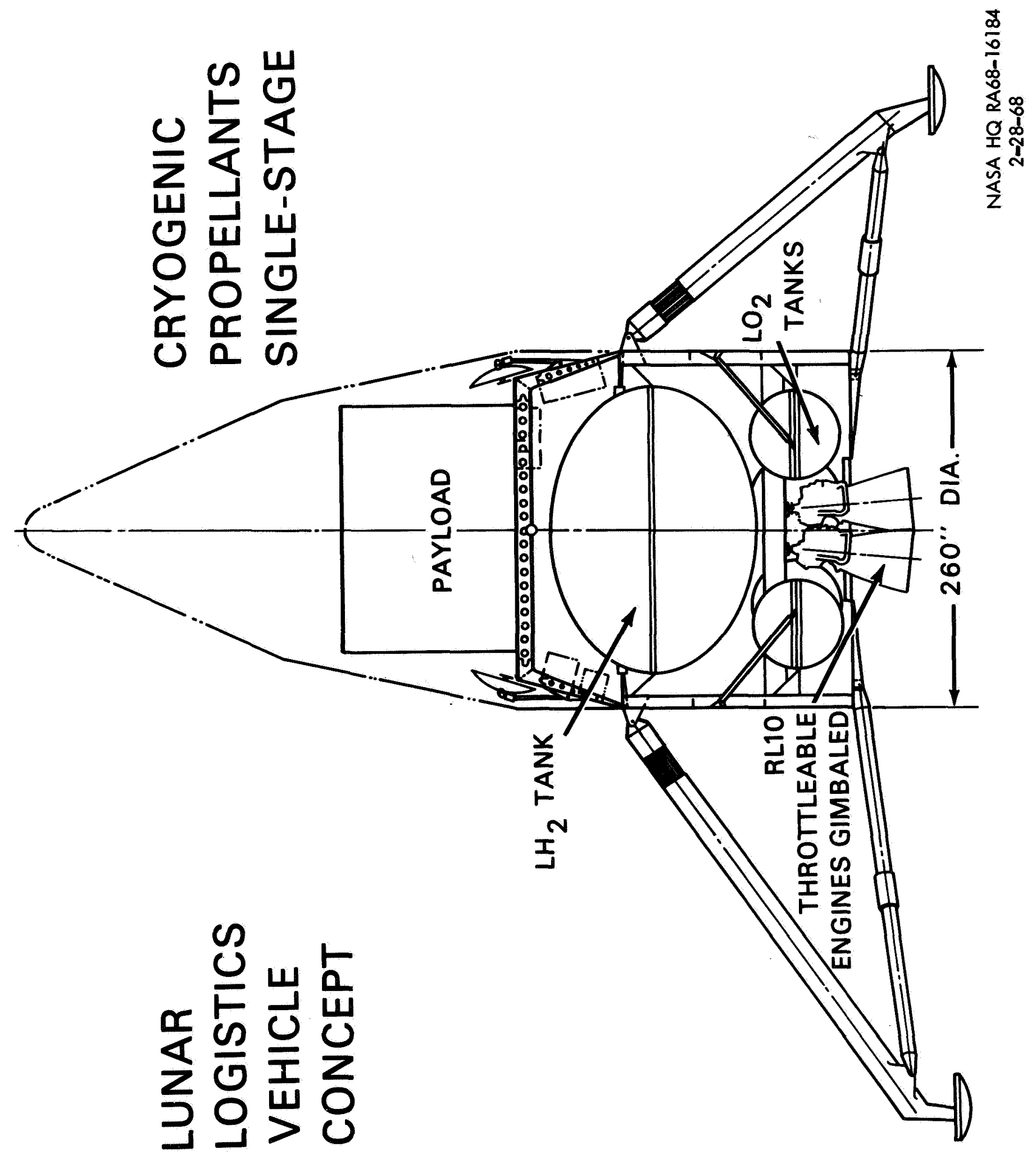




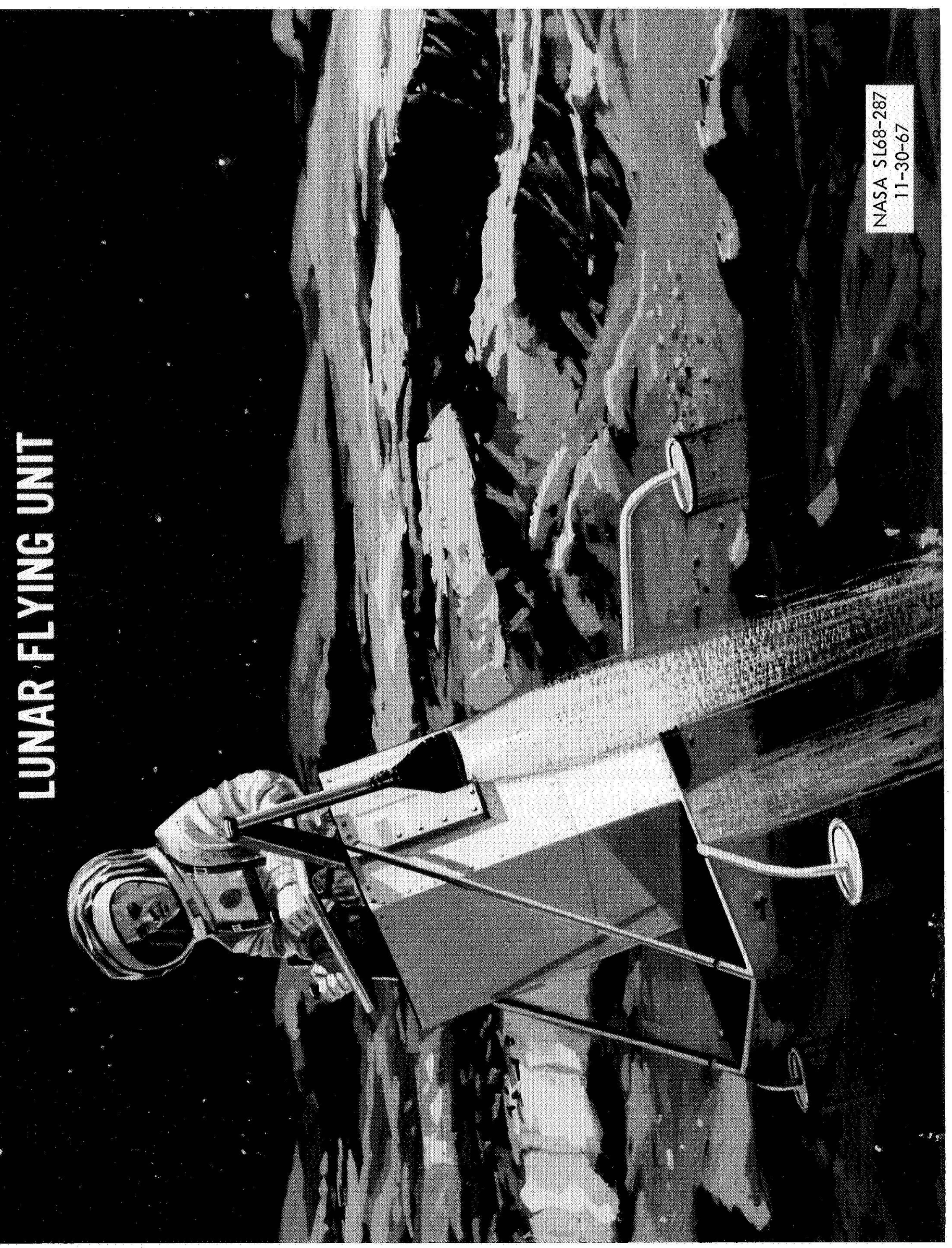




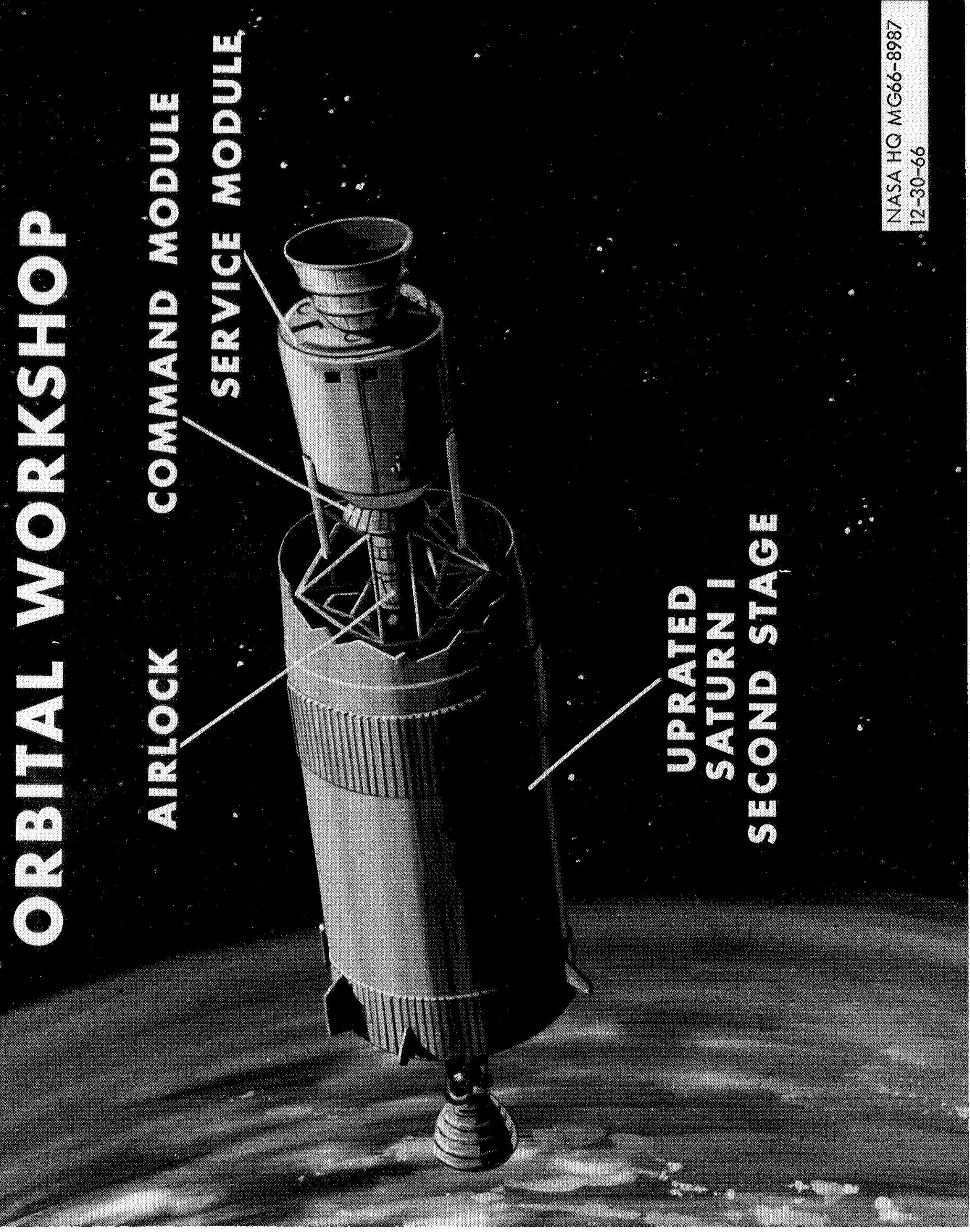




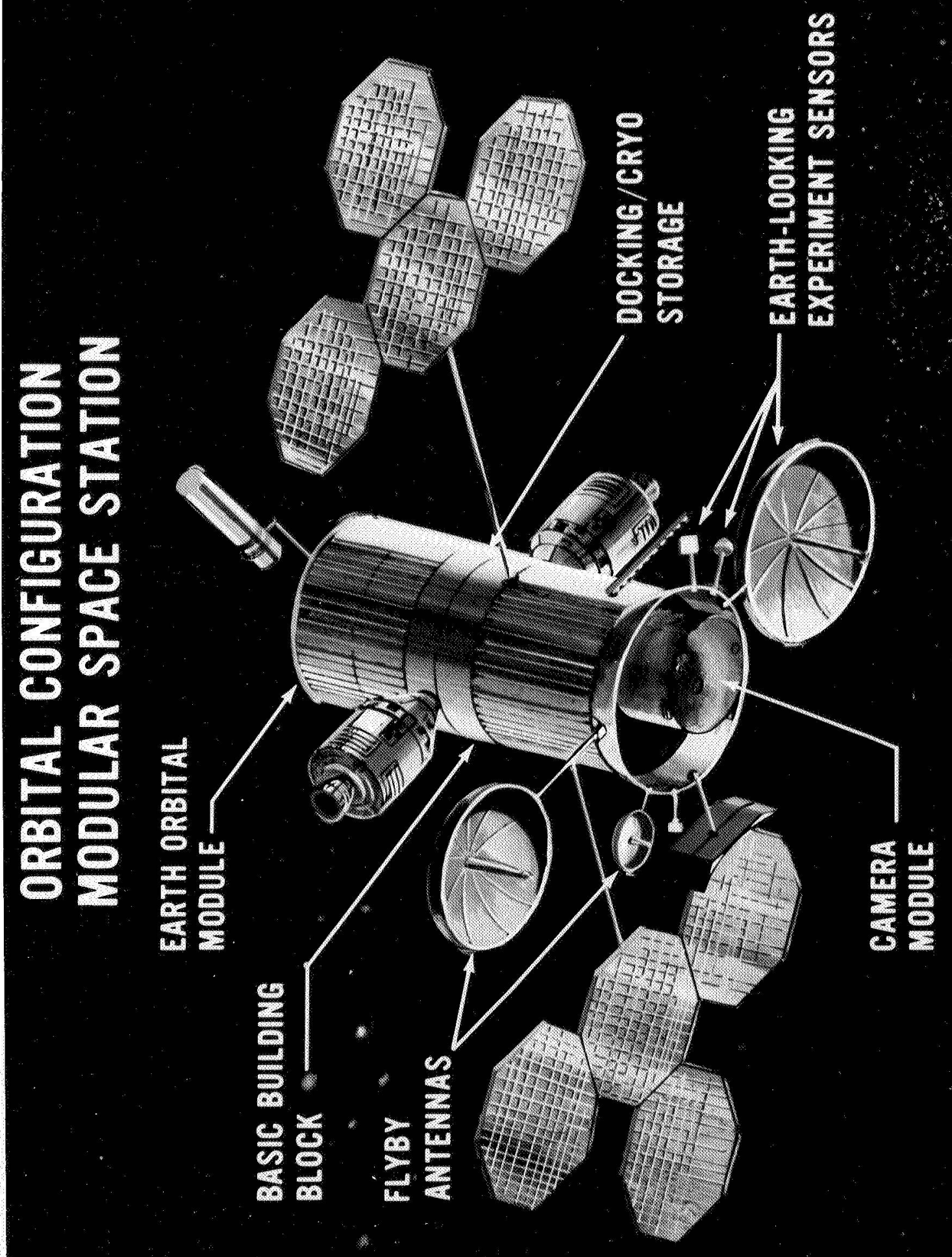




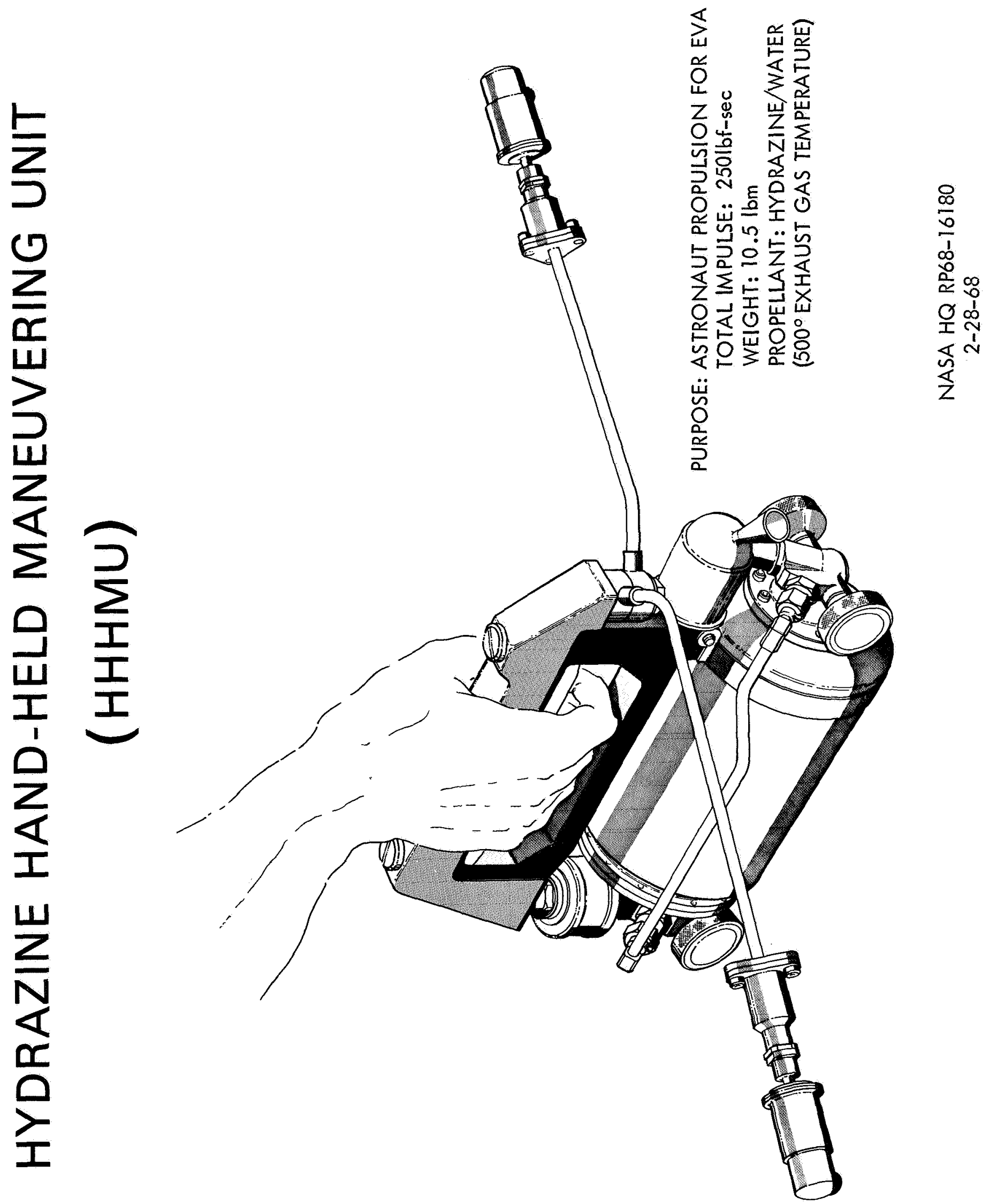



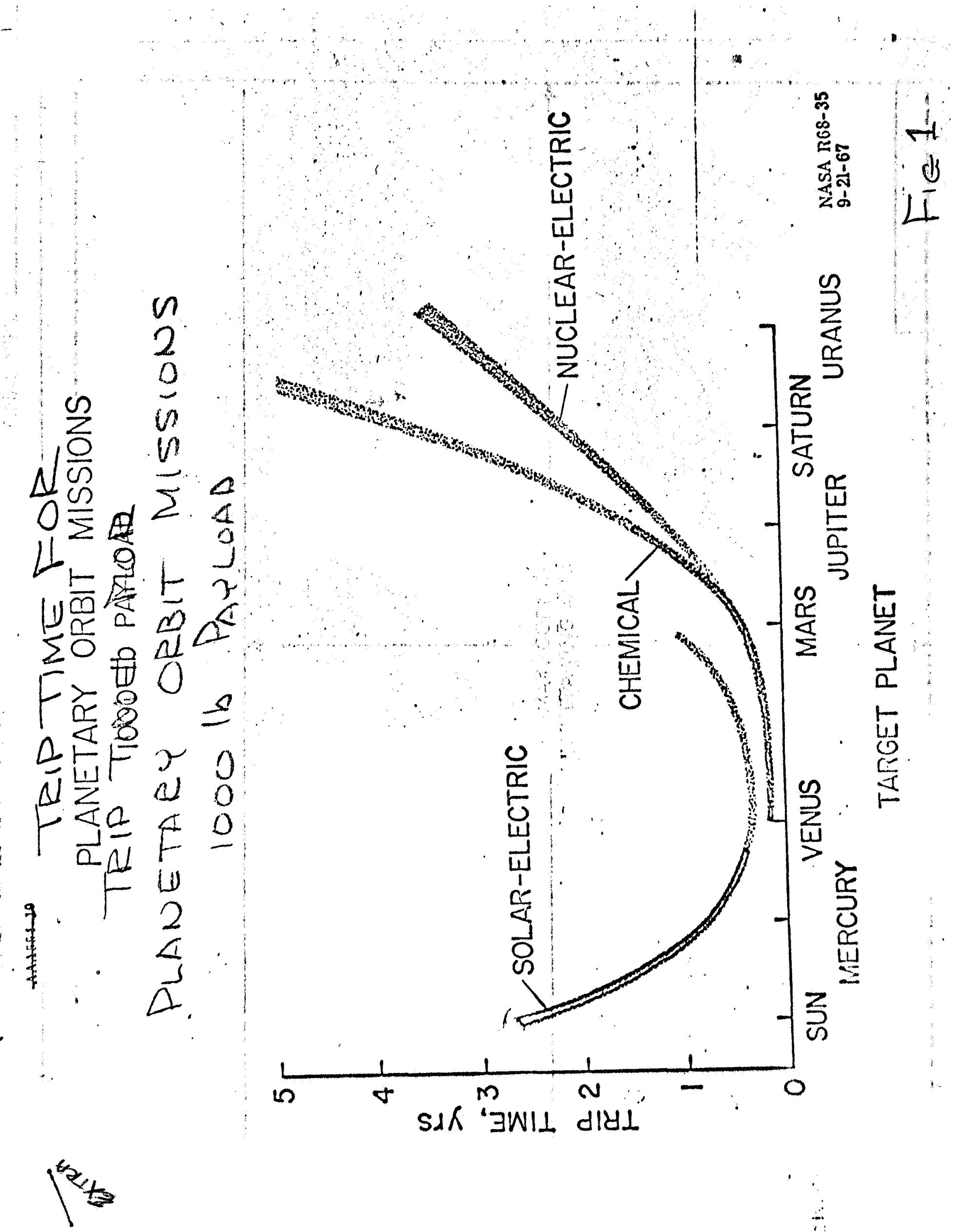


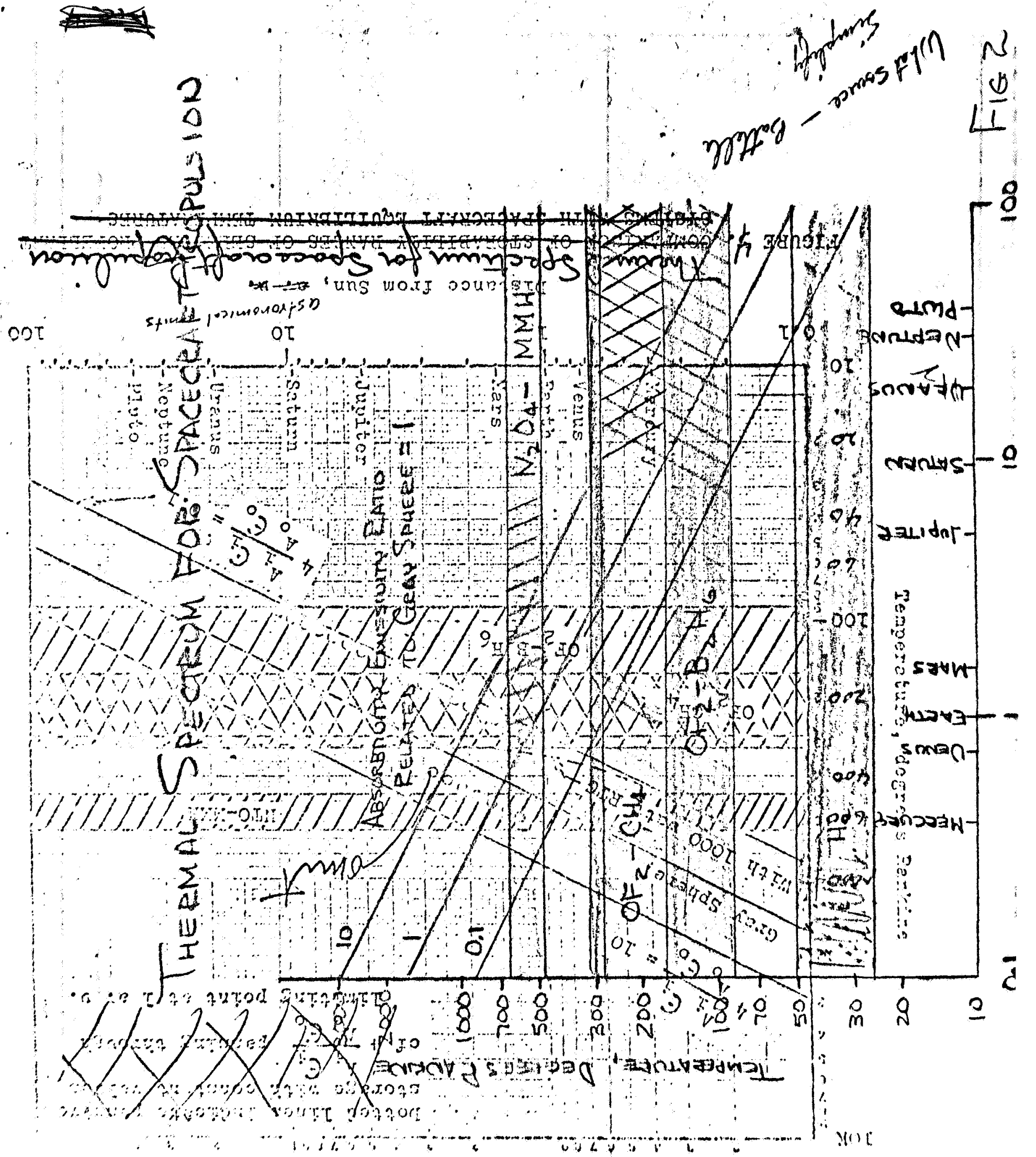




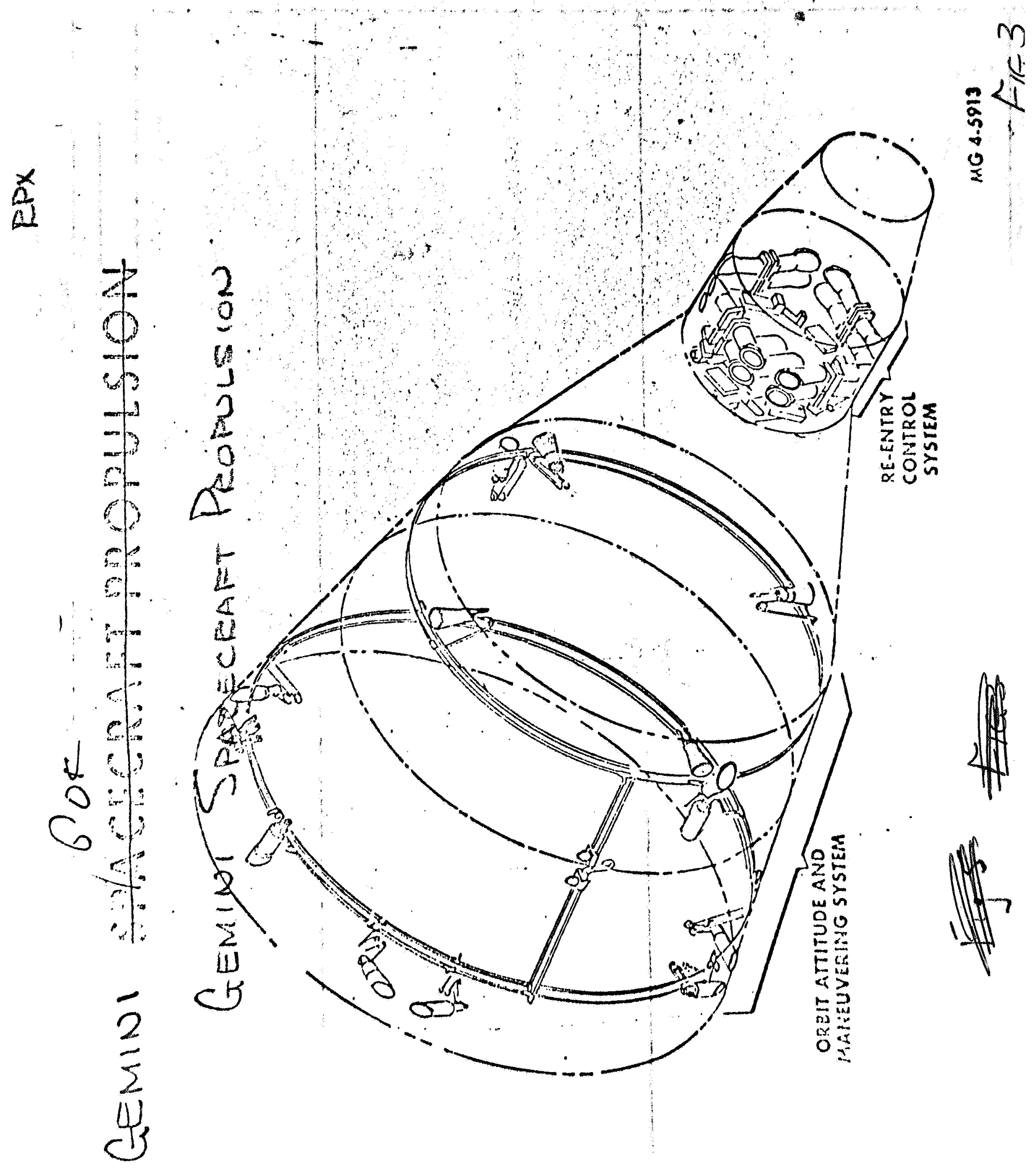




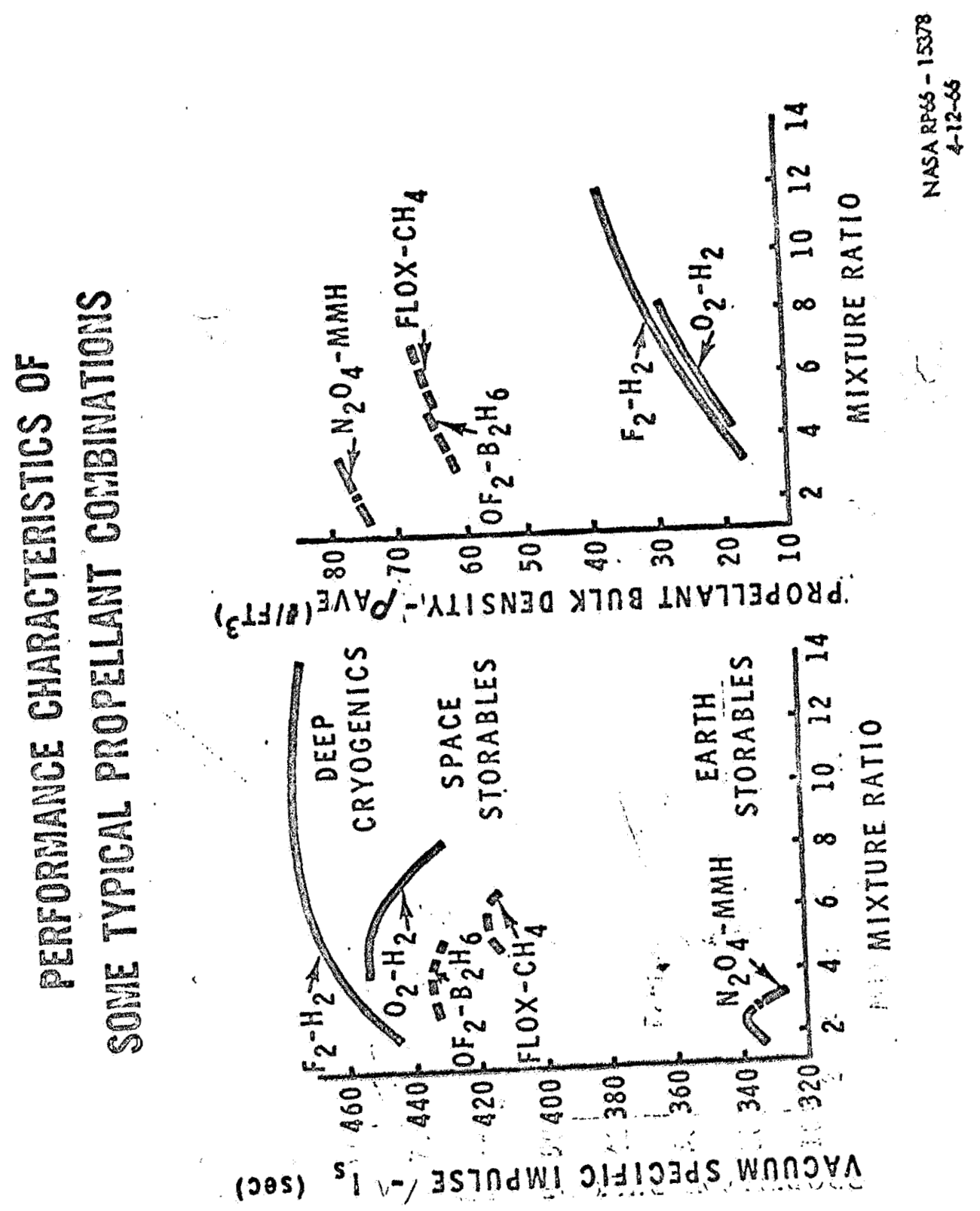




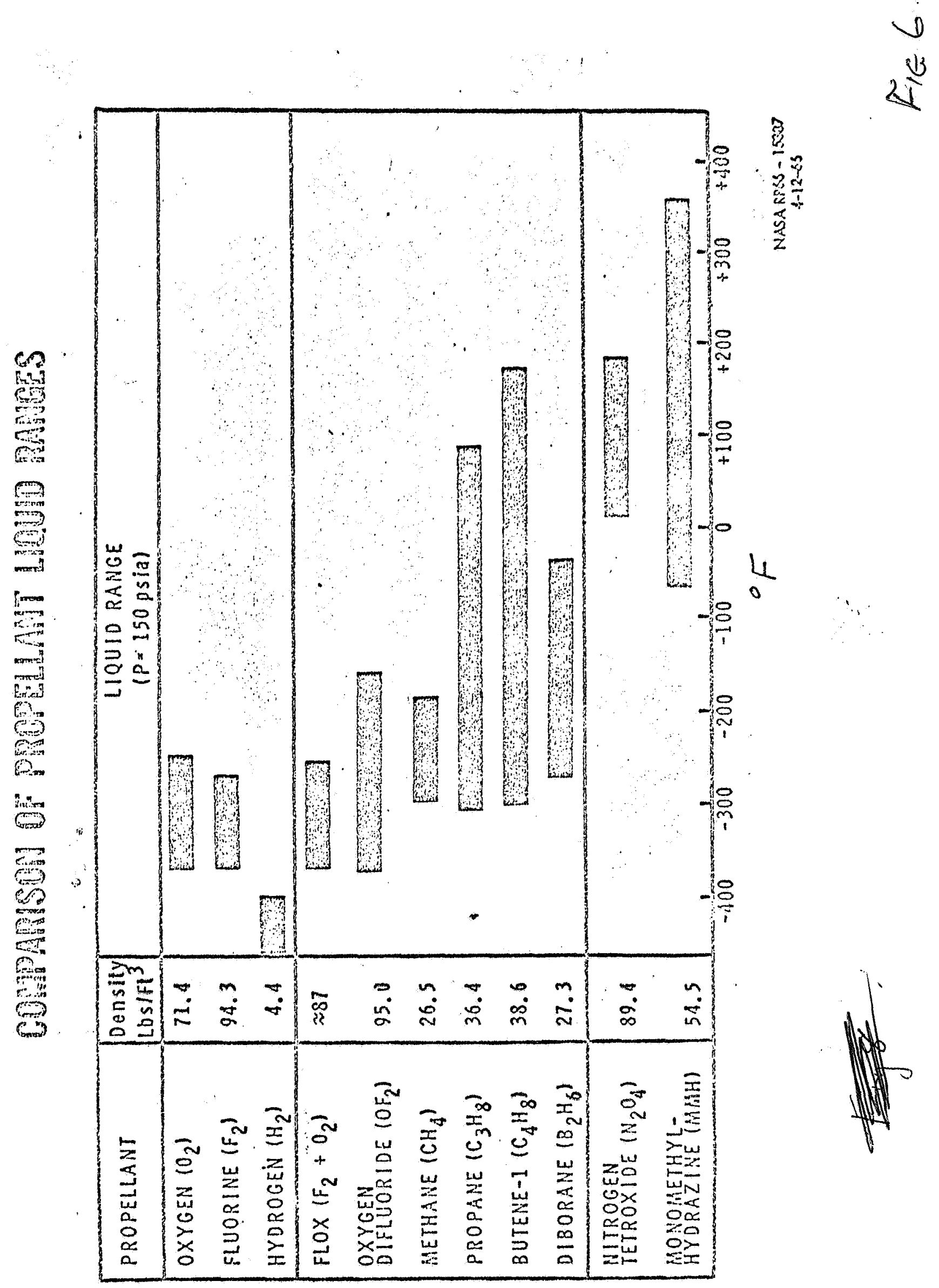




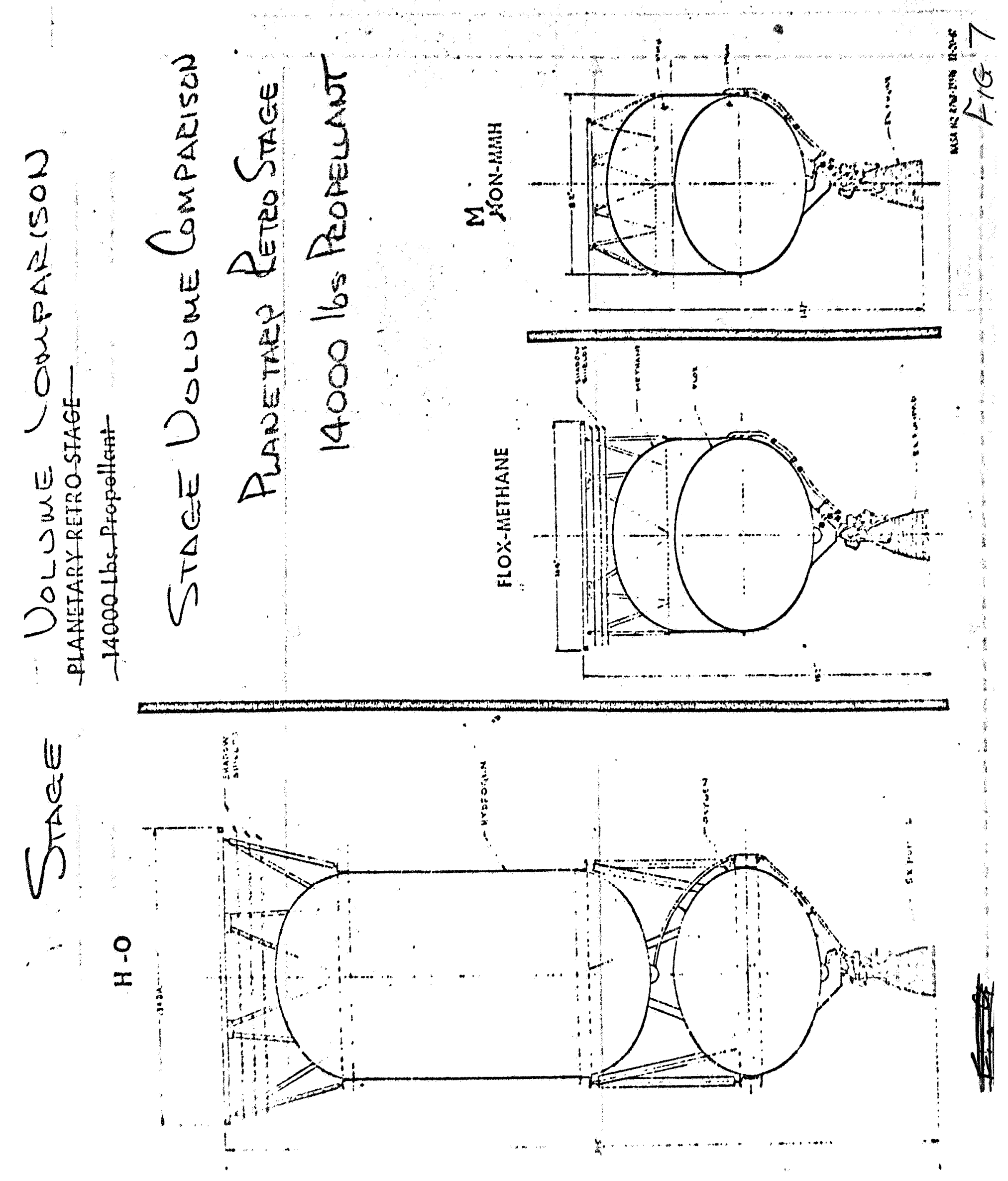



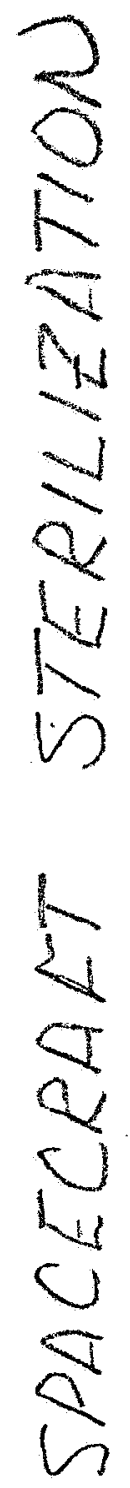

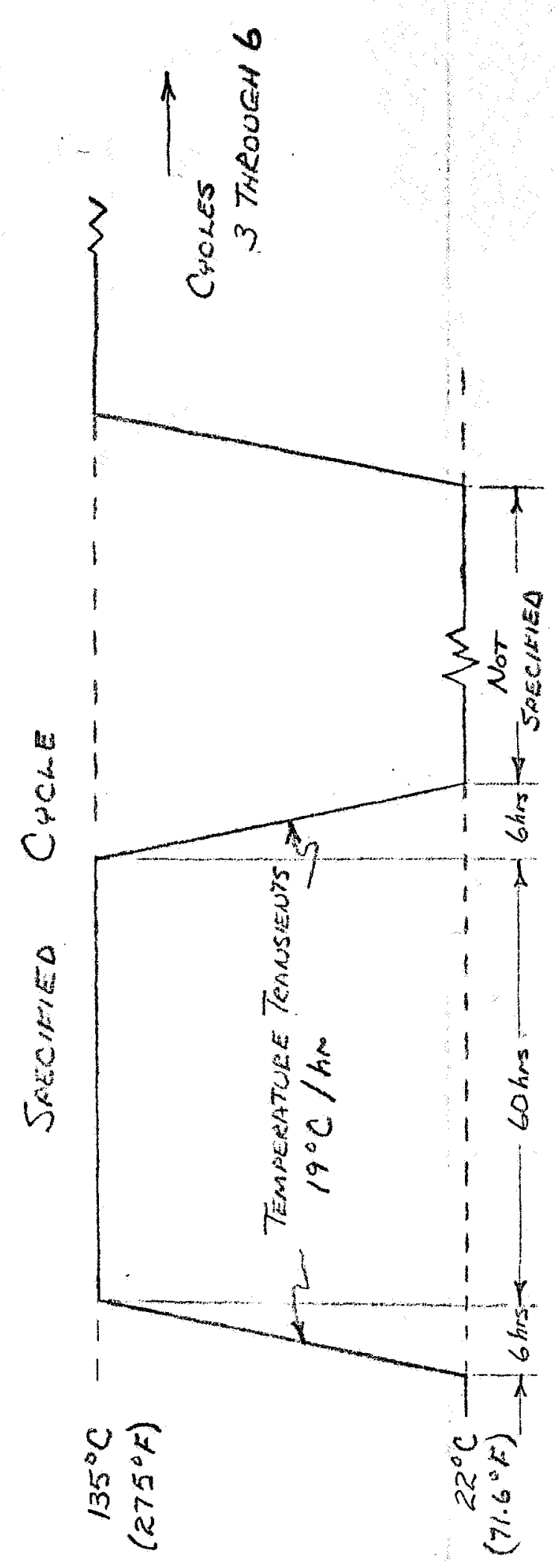

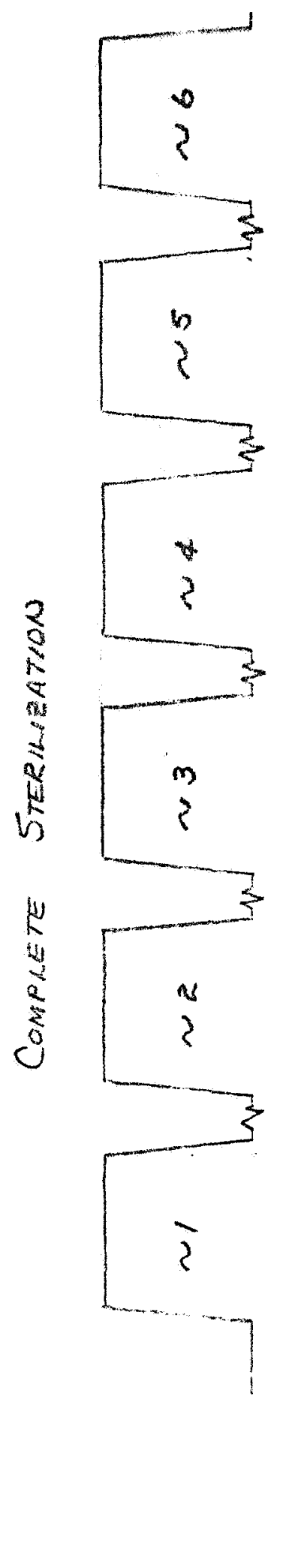


D2-114116-1

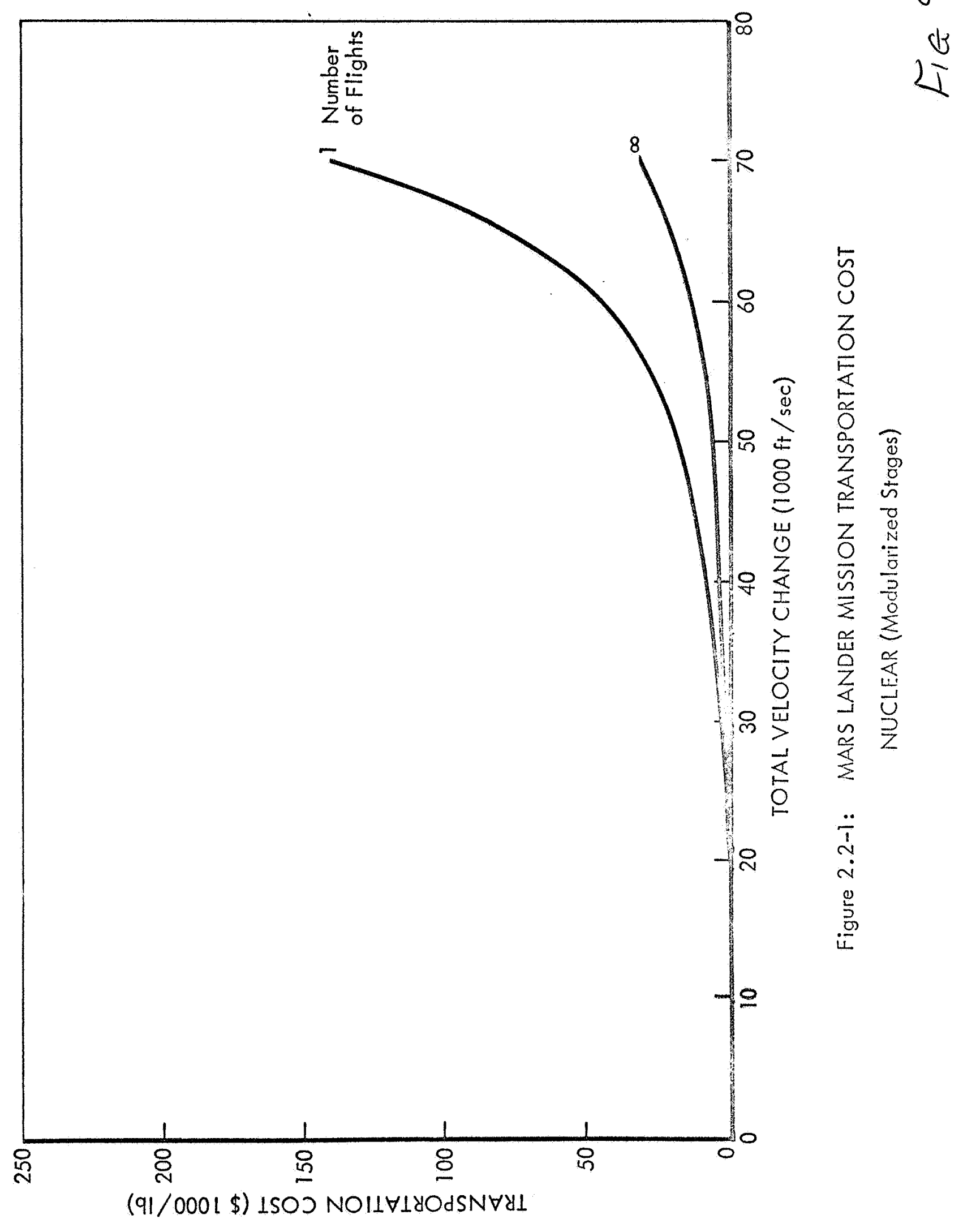




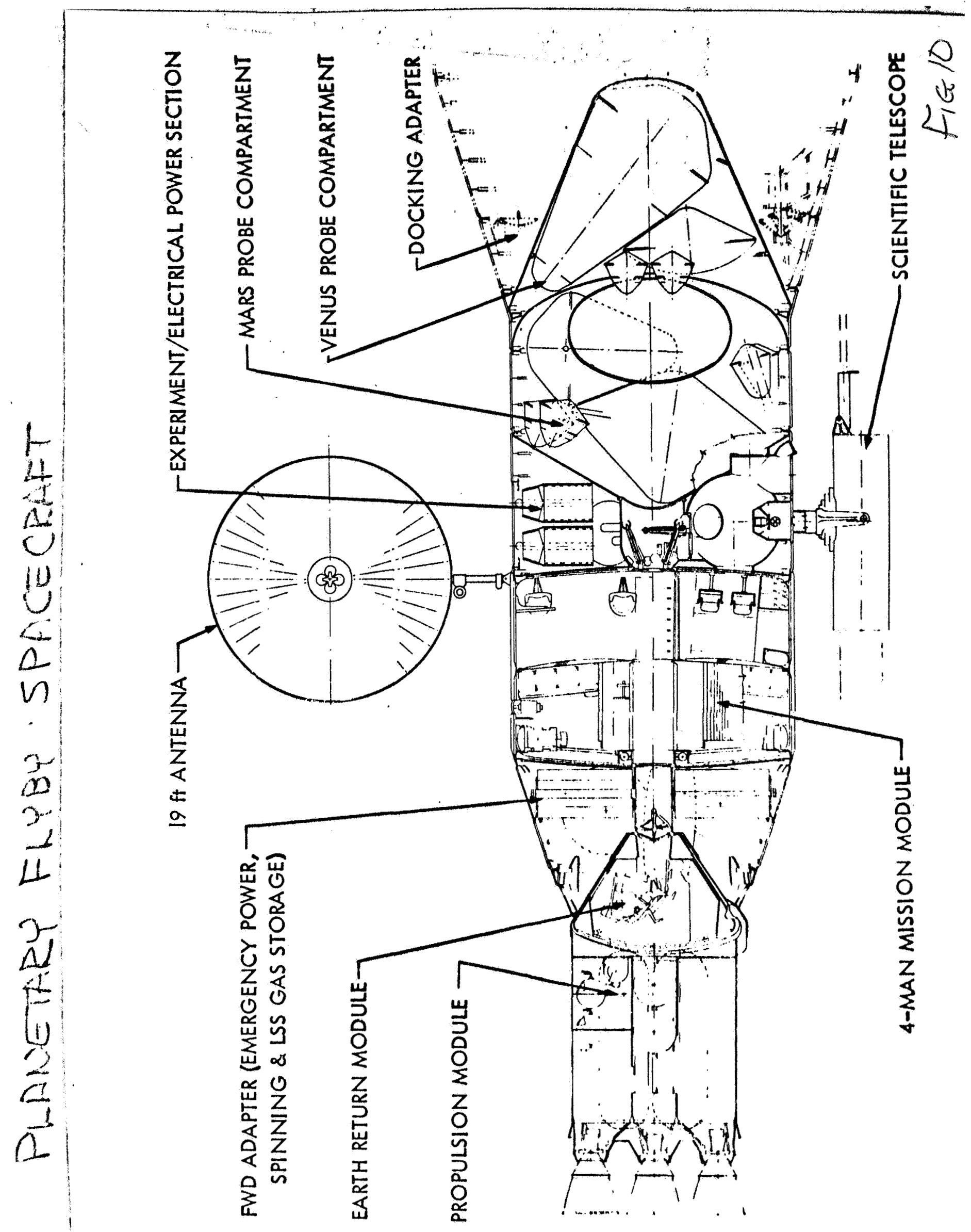




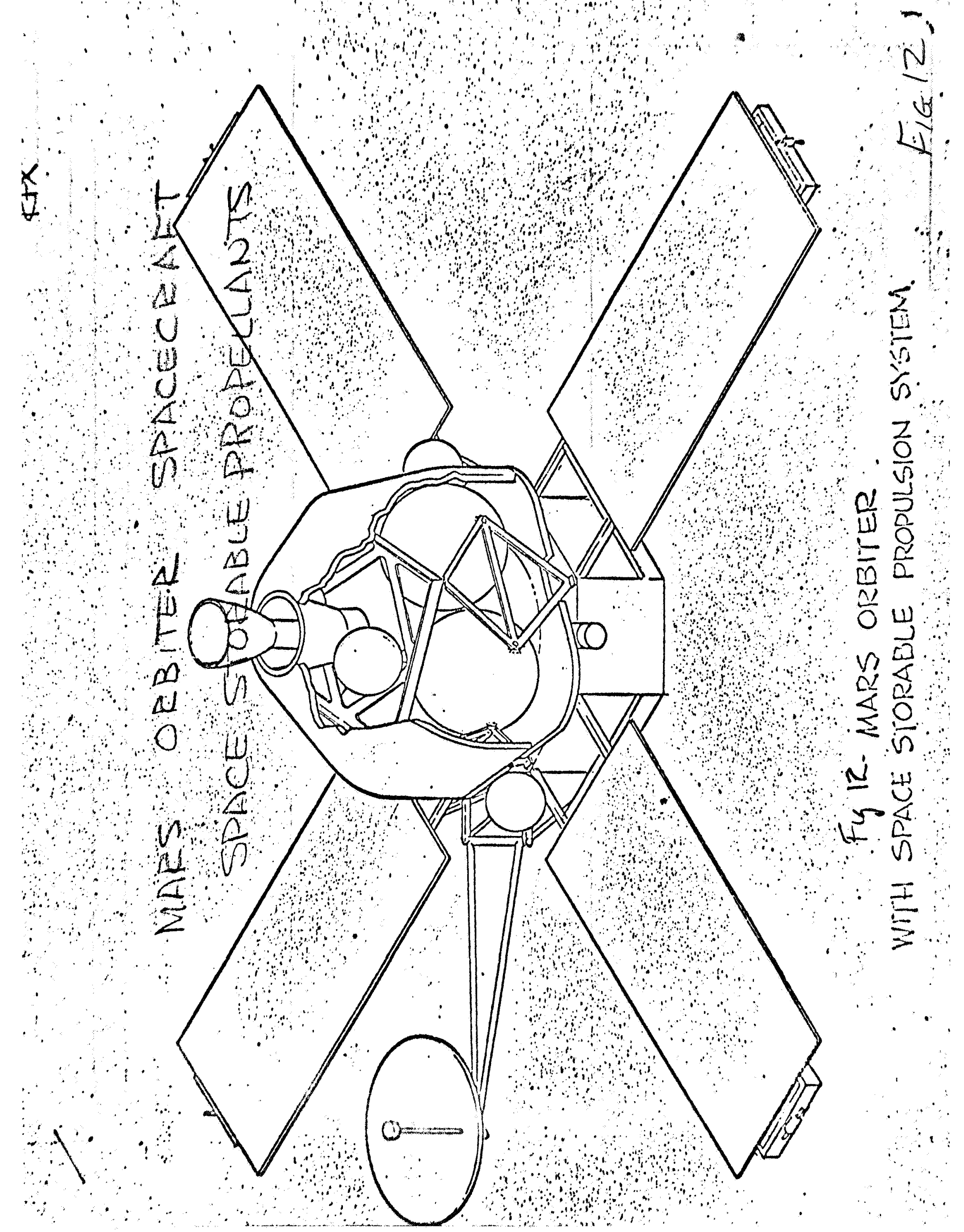




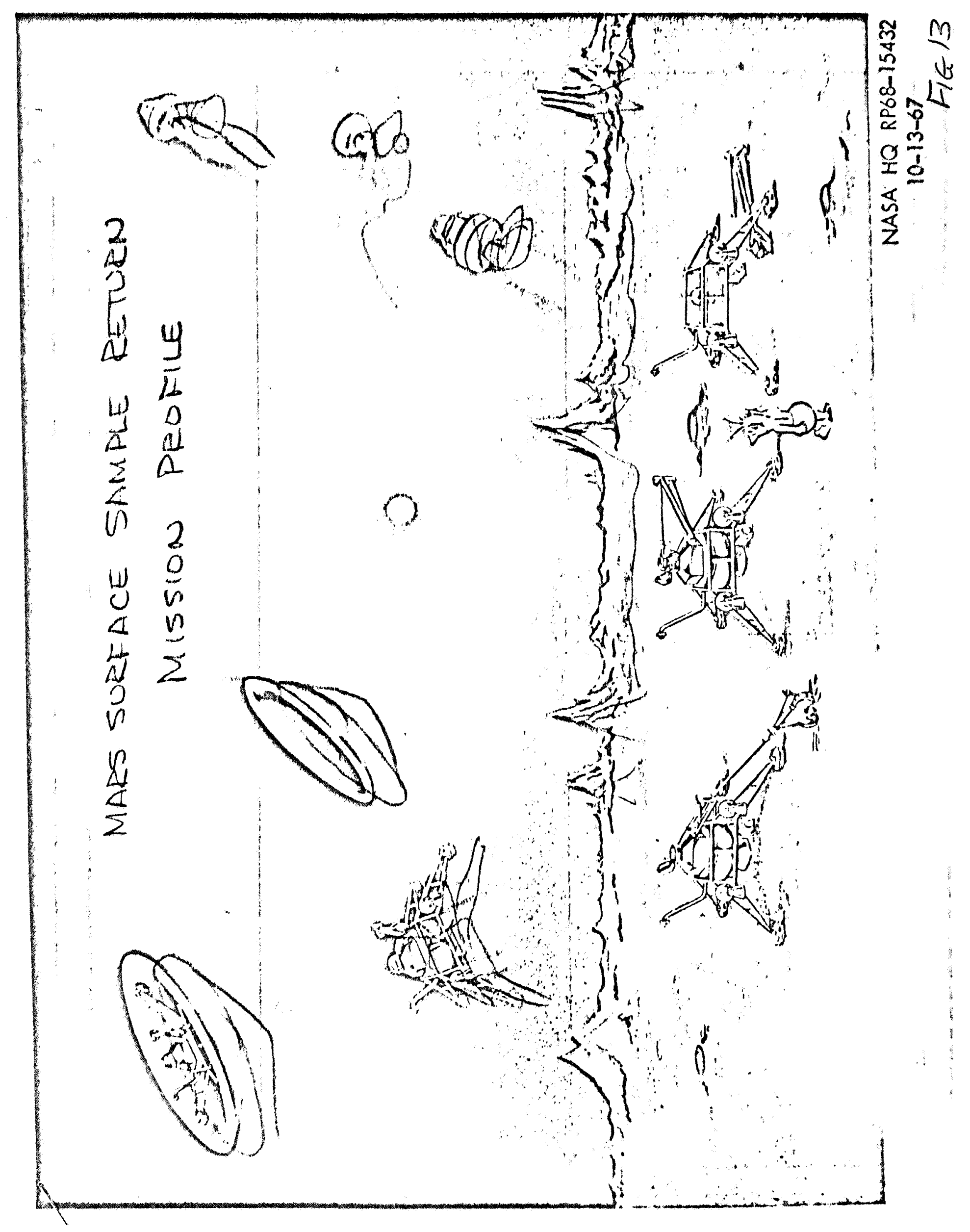




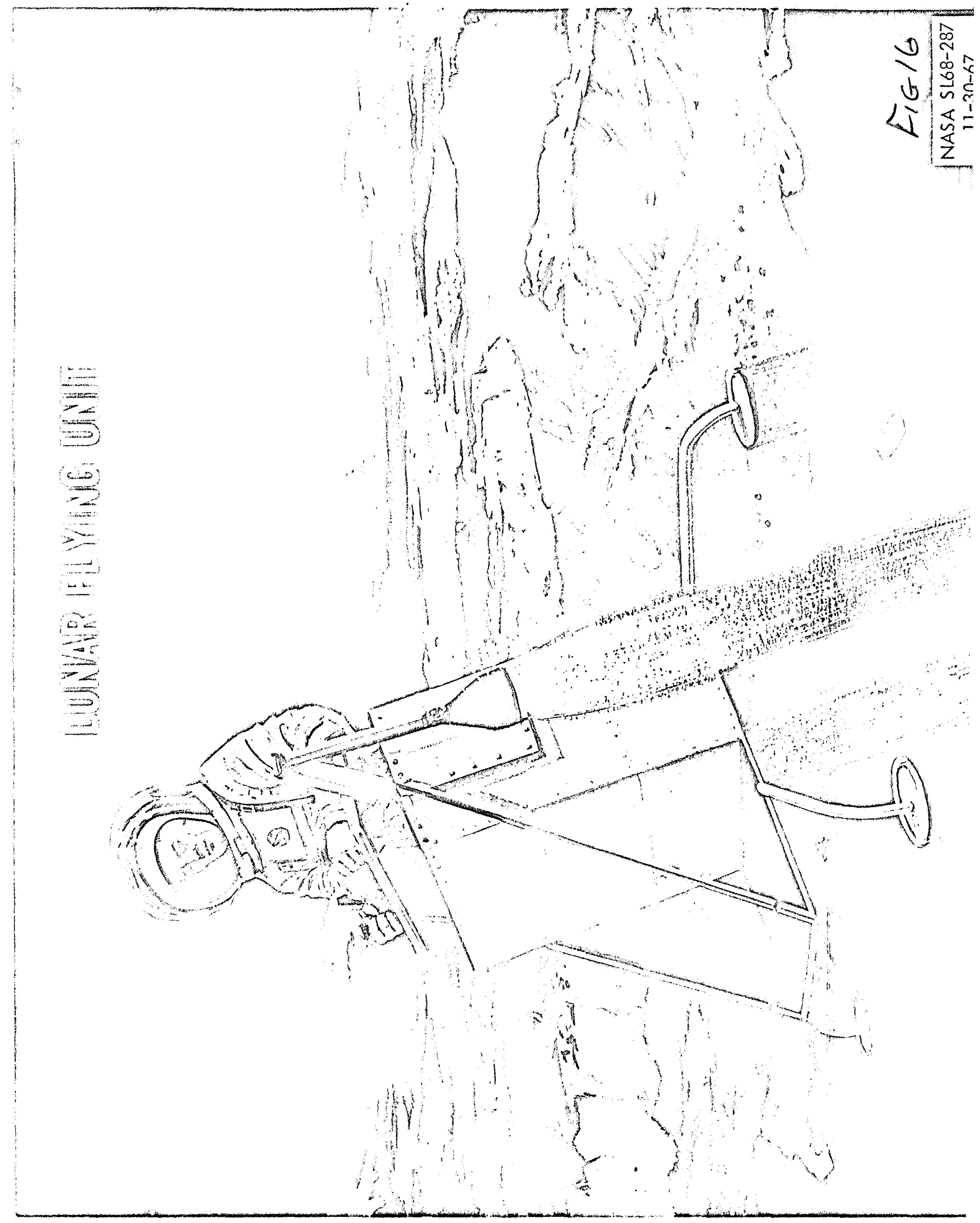




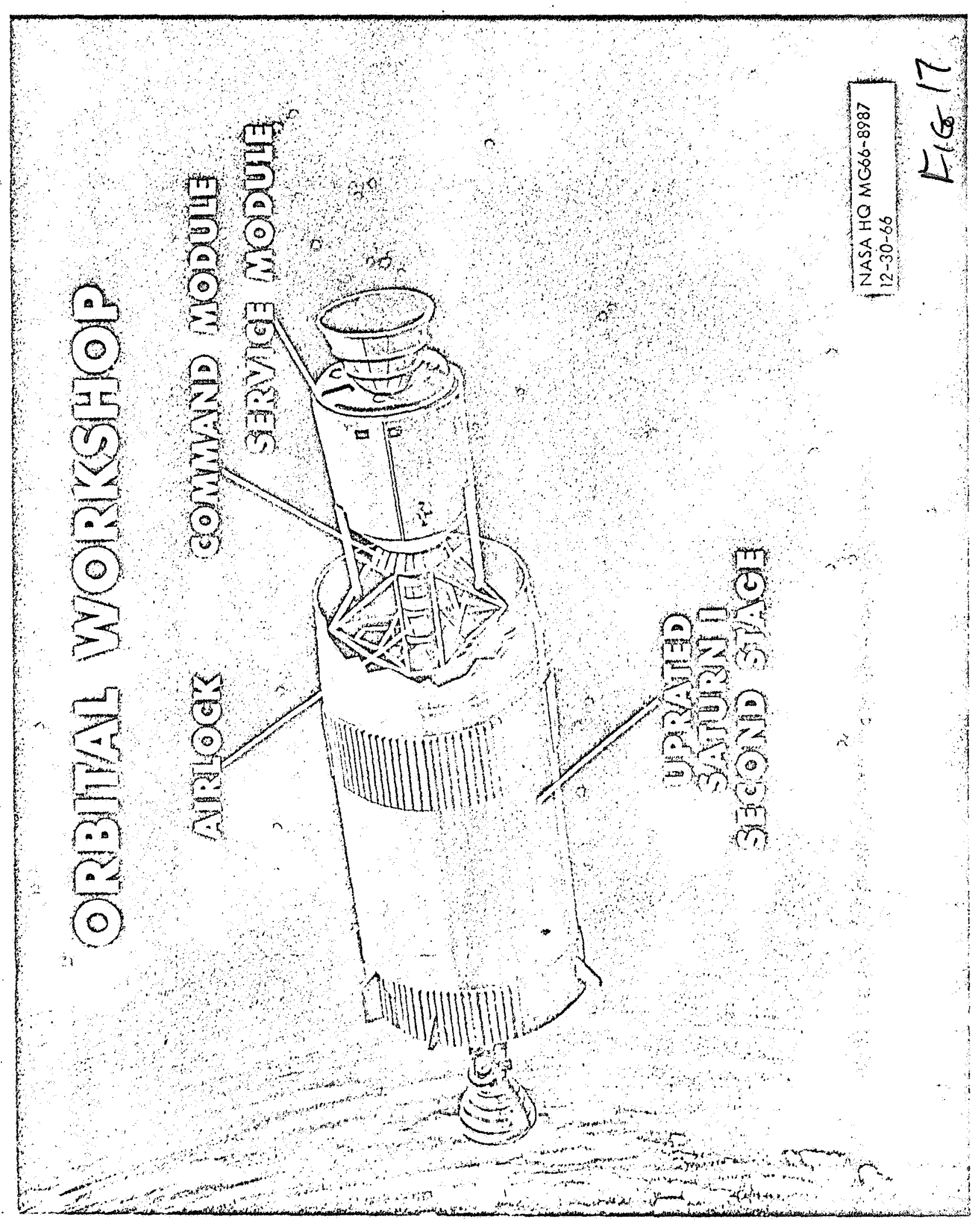




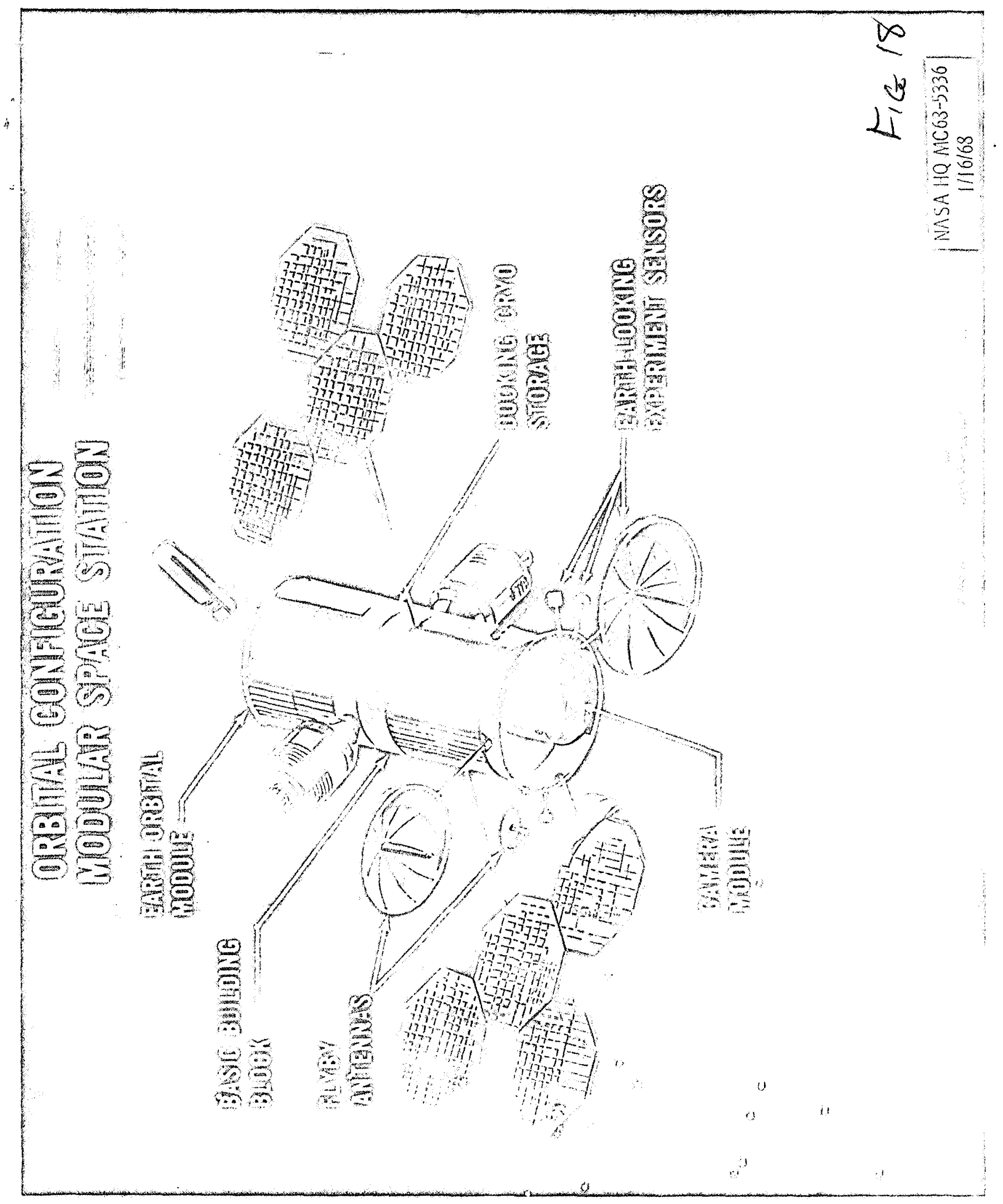




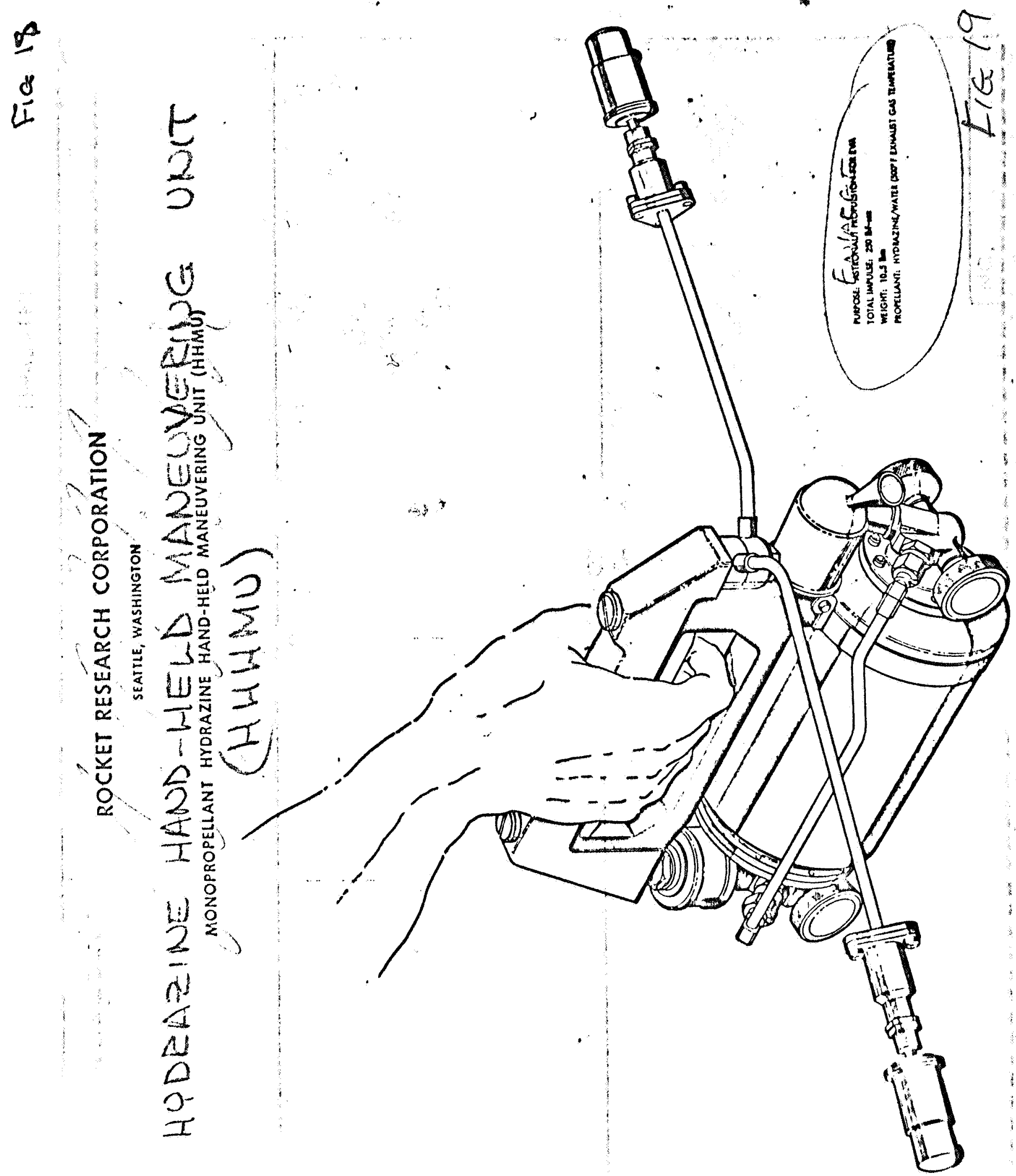

